\title{
Thermal response of mid-ocean ridge hydrothermal systems to perturbations
}

Shreya Singh and Robert P. Lowell

Department of Geosciences, Virginia Tech University, Blacksburg, Virginia 24060 


\begin{abstract}
Mid-ocean ridges are subject to episodic disturbances in the form of magmatic intrusions and earthquakes. Following these events, the temperature of associated hydrothermal vent fluids is observed to increase within a few days. In this paper, we aim to understand the rapid thermal response of hydrothermal systems to such disturbances. We construct a classic single-pass numerical model and use the examples of the 1995 and 1999 non-eruptive events at East Pacific Rise (EPR ) 9050' N and Main Endeavour Field (MEF), respectively. We model both the thermal effects of dikes and permeability changes that might be attributed to diking and/or earthquake swarms. We find that the rapid response of vent temperatures results from steep thermal gradients close to the surface. When the perturbations are accompanied by an increase in permeability, the response on the surface is further enhanced. For EPR9 50 ' N, the observed $\sim 7^{\circ} \mathrm{C}$ rise can be obtained for a $\sim 50 \%$ increase in permeability in the diking zone. The mass flow rate increases as a result of change in permeability deeper in the system, and, therefore, the amount of hot fluid in the diffused flow also increases. Using a thermal energy balance, we show that the $\sim 10{ }^{\circ} \mathrm{C}$ increase in diffuse flow temperatures recorded for MEF after the 1999 event may result from a 3-4 times increase in permeability. The rapid thermal response of the system resulting from a change in permeability also occurs for cases in which there is no additional heat input, indicating that hydrothermal systems may respond similarly to purely seismic and noneruptive magmatic events.
\end{abstract}

\title{
KEYWORDS
}

Hydrothermal systems, diking, East Pacific Rise, Main Endeavour Field, perturbation, singlepass model, 1-D model. 


\section{Introduction}

Hydrothermal systems essentially consist of a heat source and a fluid circulation system. For high-temperature hydrothermal systems at oceanic spreading centers, the heat comes primarily from the emplacement of magma bodies in the shallow crust. The circulating fluid is mainly seawater, with some input of magmatic volatiles. In the simplest scenario, seawater enters the crust through faults and fractures and descends along permeable pathways to near the top of the magma body where it reaches temperatures exceeding $400^{\circ} \mathrm{C}$ (Kelley et al., 2012). The heated fluid then ascends through other permeable faults or fracture zones and emerges at the seafloor as mineral-rich "black smoker" vents. The temperature and composition of fluids collected at some of these vents may remain quasi-steady over months or even years (e.g., Bio9 vent, East Pacific Rise (EPR) 9050' N (Von Damm, 2004), Main Endeavour Field (MEF), (Lilley et al., 2003).

Hydrothermal venting is intimately linked to the dynamic process of crustal accretion, and therefore, from time to time, the output of such systems is affected by perturbations. Crustal accretion at mid-ocean ridges is a complex process which, in the simplest scenario, is a diking event (e.g., Delaney et al., 1998), where magma is emplaced as a longitudinal intrusion into the overlying oceanic crust. Dikes are often detected due to an increase in seismicity in their vicinity. Such intrusions add localized heat to the system, and the changes in the near-field stress distribution may result in permeability changes that affect the circulation of the hydrothermal fluids (Craft et al., 2014). Both these factors lead to an increase in the output of the hydrothermal system resulting in changes to the temperature and salinity of the vent fluids. For small noneruptive diking events, the hydrothermal system may return to its original or slightly altered preevent state [e.g., EPR 9050' N, Fornari et al., 1998a]; however, in some cases, such perturbations may indicate a complete change in the thermal-fluid regime of the vent field and lead to permanent changes (e.g., MEF, Kelley et al., 2012). Additionally such events result in a change in seafloor fauna and vent chemistry (Shank et al., 1998; Lilley et al., 2003; Seyfried et al., 2004). 
Since new oceanic crust is formed by episodic magmatic activity, mid-ocean ridge hydrothermal systems are often subject to these disturbances. However, due to the scarcity of insitu data at vent fields, very few of these events have been monitored in real time. As these events provide us special insight into the physical, chemical and biological processes at vent fields, it is important to utilize the available data to better understand how hydrothermal systems respond to magmatic and tectonic perturbations. In this paper, we construct relatively simple yet effective numerical models of a vent field for the purpose of understanding its response to smallscale disturbances. We construct a quasi-one-dimensional single-pass numerical model and use the examples of EPR $9^{\circ} 50^{\prime} \mathrm{N}$ and MEF $47^{\circ} 57^{\prime} \mathrm{N}$, two vent fields that experienced non-eruptive diking in years 1995 and 1999, respectively, to test the model.

Sections 2 and 3 briefly describe the nature of non-eruptive events at EPR $9^{\circ} 50^{\prime} \mathrm{N}$ and MEF and the previous attempts made in order to understand the propagation of perturbations. Sections 4 and 5 entail the model and parameterization chosen to represent the EPR and MEF vent fields. The model is tested for various scenarios for both fields and the results are reported in Section 6. Section 7 contains the interpretation of the results, implications of using a simplified model and limitations of the model.

\section{Response of hydrothermal systems to perturbations at mid-ocean ridges}

In March 1995, an array of nine ocean-bottom seismometers deployed on the EPR detected a total of 283 microearthquakes situated north of the $9^{\circ} 50^{\prime} \mathrm{N}$ area and close to Bio9 and P vents (Sohn et al., 1999). Based on the hypocentral pattern, Sohn et al. (1999) considered a diking event unlikely and attributed the microearthquake activity to the release of thermal stresses at the base of the hydrothermal system. However, Ramondenc et al. (2008) and Germanovich et al. (2011) argue that the March 1995 seismic activity at $9^{\circ} 50^{\prime} \mathrm{N}$ could have resulted from a non-eruptive diking event. Germanovich et al. (2011) use numerical models to show that the dike is likely to propagate sub-vertically from the margins of the thin, lens-like magma chamber, which is characteristic of the magma chamber present below EPR. Using their model for dike propagation and hydrothermal circulation, they provide mechanical as well as

hydrothermal evidence to suggest that the 1995 event was a diking event caused by magma 
replenishment between major eruption episodes in 1991/1992 (Sohn et al., 1998) and 2005/2006 at EPR 9॰50’ $\mathrm{N}$ (Fornari et al., 2012).

A similar period of elevated seismic activity was observed in June 1999 for the Endeavour Segment (Johnson et al., 2000; Lilley et al., 2003) in which the MEF was affected most strongly (Kelley et al., 2012). The activity lasted 5-11 days and spanned the along-axis region above the magma chamber (Johnson et al., 2000). Initially, this event was thought to be of tectonic origin (Johnson et al., 2000); however, the 1999 event also caused dramatic increases in $\mathrm{CO}_{2}$ and $\mathrm{H}_{2}$ concentrations in the vent fluids (Lilley et al., 2003). As these observations indicated high-temperature water/rock reactions, Lilley et al. (2003) argued that the chemical data from the hydrothermal fluids collected in September 1999 and June 2000 was more consistent with a magmatic event. Bohnenstiehl et al. 2004 showed that the seismic activity migrated southward $12 \mathrm{~km}$ along-axis at a rate of $1.1 \mathrm{~km} / \mathrm{hour}$, thus indicating that the seismicity was the result of a lateral dike injection.

At the EPR, the temperature data collected by Sohn et al. (1998) for the Bio9 vent showed that vent temperature was stable for approximately 15 months prior to the March 1995 event at $\sim 365^{\circ} \mathrm{C}$. After the March 22 event, the vent temperature increased by $7^{\circ} \mathrm{C}$ over 8 days (Fig. 1), and gradually returned to normal after several months. Similarly at the MEF, temperatures had remained stable for nearly 10 months prior to the earthquakes after which Johnson et al. (2000) observed a temperature rise up to $\sim 10^{\circ} \mathrm{C}$ in the diffuse flow sites approximately 4-11 days after the first event on June 8, 1999 (Fig. 2). Many high temperature vents within the MEF increased by $15^{\circ} \mathrm{C}$ and some vents emitted fluids that were nearly fresh (Lilley et al., 2003; Kelley et al., 2012).

The examples listed above illustrate that seafloor hydrothermal systems are sensitive to diking events and that the temperature response is quite rapid. This is in sharp contrast with numerical models of two-phase flow in porous media subject to changes in basal heat flux (Singh et al., 2013; Choi and Lowell, 2014), in which the temperature response is strongly damped and may not be manifest for months or years after the event. Hence, the nature of the response of these vent fields to diking events might provide new insights into magma-hydrothermal processes on the seafloor. 
In both cases, the time delay between the start of seismicity and the first response of the hydrothermal system was hypothesized to reflect the time needed for the hydrothermal fluids to traverse the system (Fornari et al., 1998; Sohn et al., 1998; Johnson et al., 2000). Because the events were considered to be thermal cracking events taking place at the magma-hydrothermal boundary layer (Fornari et al., 1998; Sohn et al., 1998), this would imply that fluids travel several thousand meters in the crust in a few days or hours. Germanovich et al. (2011) and Lowell et al. (2013) show, however, that a typical mass flow rate for high temperature hydrothermal systems of $\sim 100 \mathrm{~kg} / \mathrm{s}$ would yield a hydrothermal fluid speed $\sim 10^{-5}-10^{-6} \mathrm{~m} / \mathrm{s}$ over the area of the hydrothermal discharge zone. To traverse $\sim 1000 \mathrm{~m}$ at these speeds would require several weeks, if not months, even if the speed is increased by an order of magnitude as a result of the event.

Given that the observed thermal response to non-eruptive dikes is too fast to reflect fluid transit times from deep in the hydrothermal system, the question remains as to the response mechanisms. This question has been addressed by a number of different approaches, as we outline in the next section, but important questions remain regarding the relative roles of heat input and permeability changes.

\section{Pervious modeling work}

\subsection{Thermal and pressure perturbation mechanisms}

Wilcock (2004) investigated two mechanisms that could potentially account for the hydrothermal response to the March 1995 seismic swarm at EPR 9050'N. One mechanism assumed a thermal perturbation at the base of the discharge channel that was carried by fluid ascending a vertical fracture of constant width or a cylindrical pipe of constant radius. His results showed that the observed temperature increase could be achieved by a temperature perturbation of $50^{\circ} \mathrm{C}$ at a depth of $1 \mathrm{~km}$ if fluid flowed in a single vertical crack of width $d=0.7 \mathrm{~mm}$. This would correspond to an effective crack permeability of approximately $5 \times 10^{-8} \mathrm{~m}^{2}$, assuming the relation $k=d^{2} / 12$ (e.g., Bear, 1972). To fit the temperature record, the temperature perturbation was assumed to decay linearly with time and was followed by a second, smaller thermal pulse associated with a second seismic swarm that occurred 24 days following the initial one. For this to be correct, the fluid flow in the crack would have to be $1 \mathrm{~m} / \mathrm{s}$ and the travel time would be 
$10^{3} \mathrm{~s}$. Wilcock proposed that the delayed thermal response results from the disequilibrium between the temperature of the fluid in the crack and the wall rock.

The second mechanism attributed the thermal response to pressure perturbations that could arise from a decrease in porosity. However, this could be made to fit the observed thermal response only when the permeability value of the discharge zone was $<10^{-14} \mathrm{~m}^{2}$. He noted that such permeability value was considerably less than typically thought for high temperature hydrothermal systems (e.g., Lowell and Germanovich, 1994, 2004; Wilcock and McNabb, 1996) and hence, favored the thermal perturbation mechanism. The analysis of Wilcock (2004) was done before heat flow data were available to constrain the flow rate, permeability, and other parameters related to the EPR hydrothermal system (Ramondenc et al., 2006; Lowell et al., 2013).

Following the data published in Ramondenc et al. (2006), Germanovich et al. (2011) used a planar parallel crack calculation to show that, with reasonable values of permeability, flow rate and other parameters, using the thermal perturbation model of Wilcock (2004) would yield a response time $\sim 4 \times 10^{8} \mathrm{~s}$ or $\sim 12$ years, which is much too long. Alternatively, to obtain a response time given by Wilcock [2004], the permeability would have to be much greater than appears reasonable based on the observed temperature and heat flux at EPR 9050' N. Therefore, the rapid response observed at EPR 9050' $\mathrm{N}$ could not be attributed to a thermal perturbation deep in the system with fluid traversing $1000 \mathrm{~m}$ through a crack system.

\subsection{Effect of a thermal boundary layer and permeability changes associated with diking}

In order to address the rapid response time of the thermal perturbation at EPR $9^{\circ} 50^{\prime} \mathrm{N}$, Ramondenc et al. (2008) suggested that the thermal response had a shallow origin in the crust. To test this idea, they constructed a 2-limb single-pass model to take into account both deep and shallow recharge and the resulting focused and diffused flow at the surface. In their model, mixing between cold seawater and hot hydrothermal fluid formed a thermal boundary layer in the 'mixing zone' which they placed within the top $100 \mathrm{~m}$ of the crust, to represent layer $2 \mathrm{~A}$ extrusives. At an arbitrary point within this zone, they measured the temperature of the hightemperature fluid considered to represent focused flow, taking into account some small amount of mixing between seawater and the rising hot hydrothermal fluid. They also assumed that 
diffuse flow resulted from additional mixing between seawater and high-temperature fluid and that another boundary layer existed near the seafloor where this mixed fluid exited at a temperature corresponding to diffuse flow. The result of this model was that a change in the temperature in the mixing zone would result in a rapid response at the surface, as the perturbed fluid only had to traverse a relatively short distance within the extrusives. Ramondenc et al. (2008) argued that modest increases in permeability occurring near the dike were sufficient to generate observable thermal perturbations to the boundary layer in the mixing zone. The increased temperature in the black smoker fluid induced additional mixing with seawater that led to a subsequent decrease in the perturbed temperature at EPR $9^{\circ} 50^{\prime} \mathrm{N}$ (Fig. 1).

In Ramondenc et al. (2008), however, the mass flow rate for EPR 9 50 ' $\mathrm{N}$ was assumed to be between $14-26 \mathrm{~kg} / \mathrm{s}$, which is much lower than the value of $\sim 80 \mathrm{~kg} / \mathrm{s}$ estimated by Germanovich et al. (2011) and Lowell et al. (2013). These values resulted in a lower heat flux and permeability than estimated for EPR. Germanovich et al. (2011) further addressed the magmatic origin of the EPR thermal perturbation by modeling dike propagation from the magma lens and using values of mass flux based on heat output data in Ramondenc et al. (2006) to estimate flow resistances in the recharge and discharge limb. Germanovich et al. (2011) emphasized that it was the change in permeability associated with diking that caused the observed rapid perturbations and not the presence of the thermal boundary layer in the mixing zone, as they did not observe a rapid response when cracking was not included. Additionally, their model used geometrical parameters of EPR $9^{\circ} 50^{\prime} \mathrm{N}$ and the diking event of 1995, and therefore was constrained by observational parameters (dike width and height) associated with that particular event.

\subsection{Motivation}

Although we agree with the basic premise of Ramondenc et al. (2008) and Germanovich et al. (2011) that changes in permeability in the diking zone can produce a rapid thermal response on the surface, we believe that the rapid response results from both the increase in permeability and presence of a thermal boundary layer close to the surface. These boundary layers result in steep gradients in temperature close to the seafloor. As a result of the increase in permeability due to diking, the flow rate changes quickly, which causes hotter fluids within the near-surface boundary layers to emerge on the seafloor. 
The treatment of the boundary layer here is different from that in Ramondenc et al. (2008) and Germanovich et al. (2011) in which the thin, shallow mixing zone serves as the boundary layer for high temperature flow. Above this zone, the mixed fluid cools to the diffused flow temperature in a near-surface boundary layer. Here, we use a classical single-limb single pass model and assume the boundary layer for high-temperature discharge results by applying a mixed or 'radiative' boundary condition at the seafloor (Carslaw and Jaeger, 1959). The diffuse flow component of the flow is not considered in the model. The details of the single pass model and equations are provided in the Supplementary Material.

In the single pass model, high-temperature hydrothermal fluid rises nearly isothermally until it is affected by the radiative boundary condition which cools the fluid to observed black smoker temperatures. This allows the fluid to cool both conductively and advectively, depending upon its velocity, and has been used previously in hydrothermal models of the seafloor (Germanovich et al., 2001). .As high temperature hydrothermal fluid comprises nearly 80-90\% of the hydrothermal heat output from mid-ocean ridge systems (Lowell et al., 2013), we feel that the model presented here provides us with a good understanding of such flows and their response to perturbations. We discuss the limitations of this approach in Section 7.

In the model developed here, we use acceptable values of permeability and mass flow rate, along with values of other vent field parameters (where available) for EPR and MEF and determine the response of the vent field to a diking event. In addition to modeling these particular events, by using the observational constraints available for EPR and MEF both before and after the diking events of 1995 and 1999, respectively (Table S1, Supplementary Material), we investigate a range of parameter space for the width and height of the dike and potential increases in permeability resulting from dike injection in order to understand the effects of these parameters on the thermal response. For both the EPR and MEF vent fields, we also consider the case in which there is no diking but only an increase in permeability resulting from earthquakes deep in the system.

\section{The classic single-pass model}

In the classical single-pass model of a hydrothermal circulation system, conservation of mass, momentum and energy are expressed in terms of total mass flow $Q(\mathrm{~kg} / \mathrm{s})$, mean fluid 
discharge temperature $T_{d}$, and advective heat output $H$ at the vent field scale as fluid circulation occurs through discrete pathways (e.g., Elder, 1981; Lowell et al., 2013). For a magma-driven seafloor hydrothermal system, these pathways generally consist of a deep recharge zone, a crossflow zone that transfers heat by conduction across a thermal boundary layer from a subjacent axial magma chamber (AMC), and a deep discharge zone through which the hydrothermal fluid vents to the seafloor [e.g., Lowell and Burnell, 1991; Lowell and Germanovich, 1994, 2004; Lowell et al., 2013]. The observed values of $T_{d}$ and $H$ are used to determined $Q$, and the observations of the vent field area $A_{d}$ and planform area of the AMC $A_{m}$ can be used to determine the conductive boundary layer thickness $d$ and the bulk permeability of the discharge zone $k_{d}$. The single pass model therefore provides important constraints on hydrothermal parameters at the vent-field scale. Figure 3 is a cartoon showing the assumed flow path in the single-pass model and associated symbols. The definitions of all symbols are given in Table S1 (Supplementary Material). We use these estimates of parameters for MEF and EPR 9 $50^{\prime}$ (Lowell et al., 2013) to construct a fully numerical 1-D code. The details of the model construction, mathematical formulation, boundary conditions and solution method for their model are provided in the Supplementary Material.

\section{Parameterization}

For both the EPR and MEF vent fields, the values of discharge temperature $T_{d}$ and mass flow rate $Q$ are obtained from Lowell et al., 2013. Far field surface temperature is assumed to be $0^{\circ} \mathrm{C}$ and increasing $0.05^{\circ} \mathrm{C} / \mathrm{m}$ with depth. This thermal gradient is used to calculate recharge temperature $T_{\text {rech }}$ for the vent field. The values of $T_{d}, Q$ and $T_{\text {rech }}$ along with other thermodynamic parameters are used to estimate the permeability $k$ for the model. For EPR, the steady state recharge temperature $T_{\text {rech }}=75^{\circ} \mathrm{C}$. The discharge temperature $T_{d}=371^{\circ} \mathrm{C}$ is obtained for mass flow rate $Q=86 \mathrm{~kg} / \mathrm{s}$ and permeability $k=5 \times 10^{-13} \mathrm{~m}^{2}$. For MEF, the steady state recharge temperature $T_{\text {rech }}=100^{\circ} \mathrm{C}$, corresponding to a deeper circulation system than EPR (Table S1, Supplementary Material). The discharge temperature $T_{d}=365^{\circ} \mathrm{C}$ is obtained for $Q=$ $246 \mathrm{~kg} / \mathrm{s}$ and permeability $k_{d}=4 \times 10^{-13} \mathrm{~m}^{2}$. These values are used to obtain the steady state solutions for EPR (Fig. 4) and MEF (Fig. 5), respectively, using equation (14) of the Supplementary Material and parameters shown in Table S1 (Supplementary Material). The steady state is used as a starting solution for the time dependent equation (Equation 9 in the 
Supplementary Material). The time dependent simulation runs until the solution stabilizes $(\sim 5$ days), and then the perturbation is introduced in the model. The dimensions of the dike are parameterized as dike width $w$ and dike height $h$ to quantify the quantity of magma emplaced and its location with respect to the surface. To take into account the cracking of surrounding rock caused by diking, $k$ is increased in the diking region. This also enables us to simulate a purely tectonic event in which case there is no magmatic intrusion $(w=0, h=0)$. All simulations run for a total of 30 days. Following sections describe the parameterization of variables for EPR and MEF respectively.

\subsection{East Pacific Rise}

Germanovich et al. (2011) apply a 2-D model to study the 1995 diking event at EPR $9^{\circ} 50^{`} \mathrm{~N}$. They use the distribution of earthquake hypocenters observed by the OBS array (Sohn et al., 1998) to visualize a sub-vertical dike with a height, $h$, of $600 \mathrm{~m}$ above the magma chamber lens and width, $w$, of $1 \mathrm{~m}$. As this dike geometry is quantified in their work from both mechanical and hydrothermal standpoints, we use the same values of $h$ and $w$ for the models of EPR 9 $50^{\prime}$ presented here. The main parameter which is varied for the model of EPR $9^{\circ} 50^{\prime}$ is the permeability in the diking zone which is increased by $10 \%-1000 \%$ from the permeability prior to dike input. As mentioned previously, the case in which there is no dike emplacement is also considered with the same range of permeability increase in the deep discharge zone. These scenarios are compared with dike emplacement that is not accompanied by increase in permeability in the diking zone. The goal is to obtain the $\sim 7^{\circ} \mathrm{C}$ rise in temperature which was observed at Bio9 approximately 4 days after the event.

\subsection{Main Endeavour Field}

Constraints for the modeling of the June 1999 event can be obtained from the various studies conducted at the MEF following the event. In-situ data collected by Johnson et al. (2000) showed that diffused-flow temperatures in the Easter Island site (located within the MEF), as at some sites outside the MEF (Fig. 2) increased within 4-11 days of the start of seismicity. Kelley et al. (2012) report that many chimneys within the MEF recorded temperature hikes of $\sim 15^{\circ} \mathrm{C}$. Additionally, Davis et al. (2001) use pressure transient data from Integrated Ocean Drilling 
Program (IODP) boreholes to suggest that the lateral dike injection at MEF spanned $40 \mathrm{~km}$ in length and $3 \mathrm{~km}$ in depth.

Although the thermal perturbation at MEF in 1999 appears to be associated with dike emplacement, the details of the diking event are not well-constrained. Consequently, we investigate potential temperature perturbations to the MEF for a range of possible diking scenarios. We consider dike widths $w=1,2,10,20 \mathrm{~m}$ (for $h=500 \mathrm{~m}$ ) to compare the effects of various amounts of magma emplacement in the crust and dike heights $h=250,500,750,1000 \mathrm{~m}$ (for $w=2 \mathrm{~m}$ ) to study the effect of dike penetration closer to the surface. We also consider increases in permeability in the diking zone ranging between 10 and $1000 \%(w=2 \mathrm{~m}, h=500$ m) of the initial permeability. Similar to the EPR case, we have modeled the MEF for increase in permeability with no dike emplacement. We aim at obtaining a response $\sim 4-11$ days after the event that is at least half $\left(\sim 7^{\circ} \mathrm{C}\right)$ of the total $15^{\circ} \mathrm{C}$ response.

\section{Numerical results}

Sections 6.1 and 6.2 present results obtained for various dike widths and heights for MEF as $w$ and $h$ are constant in all models for EPR. Section 6.3 presents the results for increasing local permeability in the perturbation zone for both EPR and MEF.

\subsection{Effect of dike width ' $w$ '}

Emplacing a thicker dike in the model for MEF adds more heat to the system. As the width of the dike is increased, the temperature in the diking zone, as well as the temperature on the surface increases (Figs. 6 and 7). It may be noted that the temperature profile both deep within the system and near the surface for dike $w=10 \mathrm{~m}$ and $w=20 \mathrm{~m}$ are overlapping. This is because the time for dissipation of latent heat of cooling for thinner dikes is $\sim 1$ day $(w=1 \mathrm{~m})$ and 4 days $(w=4 \mathrm{~m})$, respectively, whereas for thicker dikes, the time is $\sim 100$ days. Note that temperature profiles in Fig. 7 overlap when time elapsed after the diking is $\sim 4$ days. Therefore, in cases where the injected dike is $\sim 10 \mathrm{~m}$ thick, the temperature in the diking zone as well as on the surface will continue to rise steadily for months.

Although emplacement of such a large quantity of magma ( $w=10,20 \mathrm{~m})$ in the crust is improbable, the model allows us to calibrate the nature of the response of a hydrothermal system 
to both thin and thick dikes which are emplaced without an increase in permeability. For such dikes, bottom temperature increases as the dike cools which creates a pressure gradient causing a gradual increase in the $Q$ of the system. This gradual change in $Q$ is reflected in a small change in temperature on the surface. While the surface temperatures for thicker dikes are still increasing after $\sim 25$ days, the temperature profiles for thinner dikes have reached their peak showing that for $h=500 \mathrm{~m}$ and for moderate $w$, the maximum rapid perturbation on the surface is $\sim 2^{\circ} \mathrm{C}$. It should also be noted that this change is observed nearly 25 days after dike emplacement and not in the observed 4-11 day time-window. Therefore, emplacement of a larger amount of magmatic material in the crust alone cannot produce a rapid and pronounced response on the surface in a short time period. It can, however, contribute to gradual rise in temperatures over longer periods of time.

\subsection{Effect of dike height ' $h$ '}

Fig. 8 shows that placing the dike higher in the crust in the model for MEF causes the temperature in the upflow zone to be higher closer to the surface (Figs. 8 and 9). Five days after the input of the dike, the temperature increases by $0.5^{\circ} \mathrm{C}-2^{\circ} \mathrm{C}$, while the mass flow rates increases by $2-4 \mathrm{~kg} / \mathrm{s}$. Similar to when $w$ is increased, the mass flow rate and the temperature on the surface increase gradually as the dike cools. Predictably, the closer the dike is to the surface, the higher the temperature is (Fig. 9). However, the time frame of the response to the dike remains the same.

\subsection{Effect of increase in permeability ' $k$ '}

\subsubsection{In case of diking}

For both EPR and MEF, increasing the $k$ does not increase the temperature in the diking zone (Figs. 10 and 12) beyond what was calculated for the effect of heat loss from the dike, unlike the two previous cases. However, it has a significant impact on the $Q$ (Figs. 11 and 13) of the system and consequently, on the surface temperature. For EPR, the $Q$ increases by $\sim 7-10$ $\mathrm{kg} / \mathrm{s}$ (Fig. 11) almost instantaneously with the dike emplacement for $50 \%$ increase in permeability. Within 1 day of diking, temperature on the surface increases by $\sim 7^{\circ} \mathrm{C}$. Similarly for $\mathrm{MEF}$, increasing k by $50 \%$ causes $Q$ to increase by $\sim 15 \mathrm{~kg} / \mathrm{s}$ and surface temperature to 
increase by $\sim 10^{\circ} \mathrm{C}$. The increase in temperature in both cases can also be observed in Figures 10 (c) and 12 (c) where there is a clear jump in temperature close to the surface.

\subsubsection{In case of no dike intrusion}

Figs. 14-17 show that even with no additional heat input from a dike, the temperatures on the surface increase rapidly when the permeability of the discharge zone increases. In such cases, temperature in the 'perturbed' zone does not increase (Figures 14A and 16A), but the temperature at the surface increases due to the increase in the mass flow rate of the system (Figs. 15 and 17). While this can be treated as a purely tectonic or a 'cracking' event, the response on the surface is not due to the exposure of the fluid to hotter rock but due to the increased rate of heat extraction from the system. This eventually leads to a decrease in temperature in the 'cracking' zone.

\section{Discussion}

\subsection{Vent-field scale single pass model}

Constructing a single-pass model for a hydrothermal vent field is quantitative, though simplified, approach to modeling at the vent-field scale. The discharging fluid flow $Q$ represents the mass flow rate of high temperature hydrothermally derived vent fluid for the entire vent field and not for individual vent structures (e.g., for EPR, Bio9 and P vents; for MEF, Hulk, Dante, etc.). As the supply of this hot fluid to each of the vent structures is dependent on local factors such as distribution of permeability, mineral precipitation, and partial mixing with cold surface recharge, the thermal response of individual vent structures is hard to determine. Lowell et al. (2013) show, however, that $80-90 \%$ of the emerging fluid has a high-temperature component driven by heat transfer from the underlying magma chamber. Therefore, studying the entire vent field and its response to perturbations provides a broad understanding of the parameters controlling the behavior of the vent field.

Another artifact of using a single-pass model is that the fluid rises to the surface essentially isothermally before it cools just underneath the surface. Therefore, although temperatures of $\approx 500^{\circ} \mathrm{C}$ are reasonable for the deep discharge zone, it is unlikely that fluids retain this temperature as close to the surface $(\sim 50 \mathrm{~m})$ as indicated in these models. Numerical 
models suggest a significant degree of mixing between the high-temperature phase-separated fluid ascending form the base of the hydrothermal system and the cooler single-phase seawater. In light of this, one might think that the effect of the boundary layer is somewhat overstated in these models due to the sharp temperature gradients close to the surface. In order to test this idea, we construct a generic model (in the Supplementary Material) with fluid discharge temperature $\approx$ $400^{\circ} \mathrm{C}$ which is reasonable for both deep discharge (Jupp and Schultz, 2002) and surface high temperature discharge (Delaney et al., 1998; Kelley et al., 2012). In this case the hydrothermal fluid cools by $\approx 30^{\circ} \mathrm{C}$ close to the surface. With this relatively smaller change in temperature too, the surface temperature responds in a way similar to that presented in this paper (Figs. S1 and S2, Supplementary Material).

\subsubsection{Decay of vent temperatures after the event}

Shallow sub-surface circulation of seawater is likely to accompany deep hydrothermal circulation. This occurs because the high-temperature plume produces lateral thermal gradients in the higher permeability of the extrusives (e.g., Lowell et al., 2013; Craft and Lowell, 2009). Ramondenc et al. (2008) use their model to argue that this shallow circulation plays the role of regulating the surface temperature of the fluids. Any additional heat in the system causes the buoyancy driving the shallow circulation to increase and the resultant enhanced flow of cold water cools the initial temperature 'pulse'. The single-limb model presented here does not take into account the shallow sub-surface mixing and cannot explain the subsequent decay of temperatures. Therefore our focus is on the initial response of the system only.

\subsubsection{Rapid response of diffused flow temperatures}

For MEF, the in-situ data is only available for the diffuse flow vent sites (Johnson et al., 2000). Diffuse flow vent fluids are derived from the sub-surface mixing of the hot vent fluids

and cold seawater circulating through the shallow crust. According to Lowell et al. (2013), the heat flux for MEF is nearly equally divided among the focused and diffused flow, and the rising hot fluid constitutes $\approx 8 \%$ of the total diffused discharge. If there is no change in permeability and temperature distribution in the extrusives associated with the event, this percentage is unlikely to change. However, if $Q$ increases as a result of change in permeability deeper in the system, then the amount of hot fluid in the diffuse flow may also increase. Additionally, Lowell 
et al. (2013) argue that the diffuse flow fluids at MEF undergo conductive cooling before they emerge on the seafloor. This would create boundary layer conditions similar to that in our model for the focused flow. Therefore, although we model only hot hydrothermal fluids, the model can be used to explain rapid changes in diffuse flow temperatures if the necessary data are available.

Using the thermal energy balance in Lowell et al. (2013) and using an increased value of $Q \approx 264 \mathrm{~kg} / \mathrm{s}$, resulting from a doubling of $k$ as obtained from our models, the temperature of the diffused flow increases by $5-6^{\circ} \mathrm{C}$. The $\sim 10^{\circ} \mathrm{C}$ increase in diffused flow temperatures recorded by Johnson et al. (2000) suggests that $Q$ may have increased to $\sim 288 \mathrm{~kg} / \mathrm{s}$, which indicates that the permeability may have increased $\sim 3$ times in the vicinity of the dike.

\subsection{Single phase modeling}

For the models presented here, the density of the fluid is calculated by assuming that the density of the fluid varies linearly with the temperature of the fluid. The mass balance equation considers this density as the bulk density of the fluid in the model. Although this simplifying assumption does not hold in the deep discharge zone where phase separation is known to occur (Butterfield et al., 1994; Von Damm, 2004), it does not change the nature of the behavior of the hydrothermal system to perturbations. This can be better understood by looking at the expression for Darcy's Law.

$$
v=-\frac{k(T)}{\eta(T)}\left[\frac{\partial P}{\partial s}-\rho(T) g\right]
$$

where $v=$ Darcy flow velocity, $k=$ permeability, $T=$ temperature, $\eta=$ viscosity, $P=$ pressure, $s=$ curvilinear coordinate, $\rho=$ density of the fluid, and $g=$ acceleration due to gravity.

Suppose that in the steady state, circulation is already established in the hydrothermal system with phase-separated fluid. Any temperature change deep in the system is a result of heat added to the system from the dike or change in permeability or heat extraction from the axial magma chamber. As additional heat is taken up by the hydrothermal fluid, on the time scale of conductive cooling of the dike, the buoyancy of the fluids will gradually increase by decreasing the $\rho(T) g$ term in the equation above. This effect is analogous to increasing the dike width $w$ as the temperature, and hence buoyancy, of the deep discharge fluid increases with increasing w. As the buoyancy term changes gradually, the velocity and the resultant mass flow rate increase 
gradually and by a small amount. This does not cause a sudden response on the surface (Fig. 7). Additionally, the phase separated region in a hydrothermal system is only $\sim 10 \mathrm{~cm}$ thick (Lewis and Lowell, 2009), and therefore we neglect it in this model.

\subsection{Rapid response of hydrothermal systems to perturbations}

The rapid response of hydrothermal systems to perturbations obtained here does not indicate that the fluid has travelled to the surface from deep within the system in a matter of days, but that deep perturbations in the system can cause shallow disturbances in the boundary layer, which are observed on the surface shortly after the event. The shallow disturbances can be attributed to the presence of the thermal boundary layer close to the surface. However, it is not only the rapidity of the response that we are interested in, but also the nature of this rapid response, which is closely dependent on the nature of the event itself.

Even when deep perturbations to a hydrothermal system are not accompanied by an increase in permeability, the temperature on the surface and $Q$ increase within a matter of days (Fig. 6-9). However, the magnitude of this change is only a few degrees $\left(\sim 1-2^{\circ} \mathrm{C}\right)$. Larger changes may require a longer time ( months) to appear on the surface. This does not match the observations at the two vent fields in question where not only was the perturbation response rapid, but was also expressed as a 'spike' or rapid increase in temperature. Such sudden changes are observed when diking is accompanied by a sudden increase in $k$ (Figs. 10-17), which causes the fluid velocity to 'jump' to a higher value. While the increase in temperature in our models seems instantaneous, during the seismic event at any vent field, the increase in permeability may also occur over a period of time, in which case it may take longer for the system to achieve its higher temperature.

In general, Figs. 6-17 show that the nature of response of $Q$ is reflected in the response of the surface temperature to the perturbation. From a mathematical standpoint, this is understandable because the boundary layer is sensitive to the velocity (or $Q$ ) of the venting fluid. From a physical standpoint, the mass flow rate $Q$ is a cumulative expression of the heat supply to the system and its geometrical configuration. This again, can be understood by looking at the expression for Darcy's Law (equation i). As additional heat is gradually picked up by the hydrothermal fluid, an increase in $w$ or $h$ results in a gradual change in the buoyancy of the 
fluids, or in other words, the $\frac{\partial P}{\partial s}-\rho(T) g$ term in the equation. However, when diking is accompanied by an increase in $k$, the response in fluid velocity is rapid due to its direct relationship with $k$ as well as a gradual increase in the buoyancy term. This change in velocity leads to a rapid change in $Q$. In the event of an actual diking, the resultant response on the surface will be some combination of the geometric details and placing of the dike, as well as the conditions under which the hydrothermal fluid cools. In the absence of dike emplacement, increase in $k$ association with earthquakes will still cause a rapid response on the surface which will result in an eventual drop in the temperature of the system.

Therefore, the presence of a thermal boundary layer close the surface can enable the system to show a rapid response to a deep-seated disturbance; however, it is the rapid increase in the permeability of the system that results in a spike in discharge temperature in hydrothermal systems.

\section{Conclusion}

The models for EPR $9^{\circ} 50^{\prime} \mathrm{N}$ and $\mathrm{MEF}$ use reasonable values of vent-field permeability and flow rates to map the "vent-field"-scale response of a hydrothermal system to non-eruptive events. We conclude that steep gradients in temperature close to the surface allow for quick perturbations to hydrothermal systems. When these perturbations are accompanied by increase in permeability due to release of seismic energy, the response on the surface is sudden and sharp in nature. As hotter fluids lie close to the surface, the increase in the velocity of the fluid (and hence the mass flow rate) causes these hotter fluids to erupt rapidly, therefore showing a rapid temperature increase on the surface. We find this to be true for both EPR 9050' $\mathrm{N}$ and MEF.

We note that the model presented here does not include the subsequent decay in temperatures as were observed at both EPR $9^{\circ} 50^{\prime} \mathrm{N}$ and MEF. For this characteristic, we defer to Ramondenc et al. (2008) and Germanovich et al. (2011) who argue that the temperature increase close to the surface drives cold fluid into the system via the shallow recharge. This cold recharge "regulates" the temperature at hydrothermal vent fields and causes the subsequent decay in the temperature spike observed. Additionally, permanent changes to a hydrothermal regime, such as decay in magma supply or continuous replenishment, are expressed on the surface over longer time periods. 


\section{Acknowledgements}

This work was supported in part by NSF Grant OCE 0926418 to RPL.

\section{References}

Bear, J., 1972. Dynamics of Fluids in Porous Media. Elsevier, New York. 764 pp.

Bohnenstiehl, D.R., Dziak, R.P., Tolstoy, M., Fox, C.G., and Fowler, M., 2004. Temporal and spatial history of the 1999-2000 Endeavour Segment seismic series, Juan de Fuca Ridge, Geochem. Geophys. Geosyst. 5, Q09003, doi:10.1029/2004GC000735.

Butterfield, D.A., McDuff, R.E., Mottl, M.J., Lilley, M.D., Lupton, J.E., Massoth, G.J., 1994. Gradients in the composition of hydrothermal fluids from the Endeavour segment vent field: Phase separation and brine loss. J. Geophys. Res. 99, 9561-9583.

Carslaw, H.S., Jaeger, J.C., 1959. Conduction of Heat in Solids, $2^{\text {nd }}$ ed., Clarendon, Oxford, U.K., 510 pp.

Choi, J., Lowell, R.P., 2014. Numerical models of phase separation in seafloor hydrothermal systems linked to heat flux from a convecting replenished magma chamber. (this issue)

Craft, K.L., Lowell, R.P., Germanovich, L., 2014. Is sudden permeability change from dike emplacement the cause of flood outbursts at Athabascs Valles, Mars? $45^{\text {st }}$ Lunar and Planetary Science Conference, The Woodlands, TX March 17-21, Abstr. \#2915.

Davis, E.E., Wang, K., Thomson, R.E., Becker, K., Cassidy, J.F., 2001. An episode of seafloor spreading and associated plate deformation inferred from crustal fluid pressure transients. J. Geophys. Res. 106(B10), 21953-21963, doi:10.1029/2000JB000040.

Delaney, J.R., Kelley, D.S., Lilley, M.D., Butterfield, D.A., Baross, J.A., Wilcock, W.S.D., Embley, R.W., and Summit, M., 1998. The quantum event of oceanic crustal accretion: Impacts of diking at mid-ocean ridges. Science 281, 222-230, doi:10.1126/science.281.5374.222 
Fornari, D.J., Shank T., Von Damm, K.L., Gregg, T.K.P., Lilley, M., Levai, G., Bray, A., Laymon, R.M., Perfit, M.R., and Lutz, R., 1998. Time-series temperature measurements at hightemperature hydrothermal vents, East Pacific Rise $9^{\circ} 49^{\prime}-51^{\prime} \mathrm{N}$ : Evidence for monitoring a crustal cracking event. Earth Planet. Sci. Lett. 160, 419-431.

Fornari, D.J., K.L. Von Damm, J.G. Bryce, J.P. Cowen, V. Ferrini, A. Fundis, M.D. Lilley, G.W. Luther III, L.S. Mullineaux, M.R. Perfit, M.F. Meana-Prado, K.H. Rubin, W.E. Seyfried Jr., T.M. Shank, S.A. Soule, M. Tolstoy, and S.M. White. 2012. The East Pacific Rise between $9^{\circ} \mathrm{N}$ and $10^{\circ} \mathrm{N}$ : Twenty-five years of integrated, multidisciplinary oceanic spreading center studies. Oceanography 25(1):18-43, http://dx.doi.org/10.5670/oceanog.2012.02.

Germanovich et al. 2000 (Cited in the text but not listed here)

Germanovich, L.N., Lowell, R.P., Astakhov, D.K., 2001. Temperature-dependent permeability and bifurcations in hydrothermal flow. J. Geophys. Res., 106(B1), 473-495, doi:10.1029/2000JB900293.

Germanovich, L.N., Lowell, R.P., Ramondenc, P., 2011. Magmatic origin of hydrothermal response to earthquake swarms: Constraints from heat flow and geochemical data, J. Geophys. Res. 116, B05103, doi:10.1029/2009JB006588.

Johnson, H.P., Hutnak, M., Dziak, R.P., Fox, C.G., Urcuyo, I., Cowen, J.P., Nabelek, J., Fisher, C., 2000. Earthquake-induced changes in a hydrothermal system on the Juan de Fuca mid-ocean ridge. Nature 407, 174-177.

Kelley, D.S., Carbotte, S.M., Caress, D.W., Clague, D.A., Delaney, J.R., Gill, J.B., Hadaway, H., Holden, J.F., Hooft, E.E.E., Kellogg, J.P., Lilley, M.D., Stoermer, M., Toomey, D., Weekly, R., Wilcock, W.S.D., 2012. Endeavour segment of the Juan de Fuca Ridge: One of the most remarkable places on Earth. Oceanography 25(1):44-61, http://dx.doi.org/10.5670/oceanog.2012.03.

Lilley, M.D., Butterfield, D.A., Lupton, J.E., Olson, E.J., 2003. Magmatic events can produce rapid changes in hydrothermal vent chemistry, Nature 422, 878-881, doi:10.1038/nature01569. 
Lowell, R.P., Burnell, D.K., 1991. Mathematical modeling of conductive heat transfer from a freezing, convecting magma chamber to a single-pass hydrothermal system: Implications for seafloor black smokers. Earth and Planet. Sci., 104, 59-69.

Lowell, R.P., Germanovich, L.N., 1994. On the temporal evolution of high-temperature hydrothermal systems at ocean ridge crests. J. Geophys. Res. 99, 565-575, doi:10.1029/93JB02568.

Lowell, R.P., Germanovich, R.P., 2004. Hydrothermal processes at mid-ocean ridges: Results from scale analysis and single-pass models, in Mid-Ocean Ridges: Hydrothermal Interactions between the Lithosphere and Oceans, Geophys. Monogr. Ser., vol. 148, edited by C. R. German et al., pp. 219-244, AGU, Washington, D. C.

Lowell, R.P., Farough, A., Hoover, J., Cummings, K., 2013. Characteristics of magma-driven hydrothermal systems at oceanic spreading centers, Geochem. Geophys. Geosyst. 14, 17561770, doi:10.1002/ggge.20109.

Ramondenc, P., Germanovich, L.N., and Lowell, R.P., 2006. Effect of magma degassing on diking processes at mid-ocean ridges, Eos Trans. AGU 87(52), Fall Meet. Suppl., Abstract B31B-1103.

Ramondenc, P., Germanovich, L.N., Lowell, R.P., 2008. Modeling the hydrothermal response to earthquakes with application to the 1995 event at 950N, East Pacific Rise, in Magma to Microbe: Modeling Hydrothermal Processes at Oceanic Spreading Centers, Geophys. Monogr. Ser., vol. 178, edited by R.P. Lowell et al., pp. 97-122, AGU, Washington, D.C.

Singh, S., Lowell, R.P., Lewis, K.C., 2013. Numerical modeling of phase separation at Main Endeavour Field, Juan de Fuca Ridge. Geochem. Geophys. Geosyst. 14, 4021-4034, doi:10.1002/ggge.20249.

Sohn, R. A., Fornari, D.J., Von Damm, K.L., Hildebrand, J.A., Webb, S.C. 1998. Seismic and hydrothermal evidence for a cracking event on the East Pacific Rise crest at $9^{\circ} 50^{\prime} \mathrm{N}$. Nature 396, $159-161$. 
Sohn, R. A., Hildebrand, J.A., Webb, S.C., 1999. A microearthquake survey of the hightemperature vent fields on the volcanically active East Pacific Rise ( $\left.9^{\circ} 50^{\prime} \mathrm{N}\right)$. J. Geophys. Res. 104(B11), 25,367-25,377.

Von Damm, K.L., 2004. Evolution of the hydrothermal system at East Pacific Rise $9^{\circ} 50^{\prime} \mathrm{N}$ : Geochemical evidence for changes in the upper oceanic crust, in Mid-Ocean Ridges: Hydrothermal Interactions between the Lithosphere and Oceans, Geophys. Monogr. Ser., vol. 148, edited by C. R. German et al., pp. 285-304, AGU, Washington, D. C.

Wilcock, W.S.D., McNabb, A., 1996. Estimates of crustal permeability on the Endeavour segment of the Juan de Fuca mid-ocean ridge, Earth Planet. Sci. Lett. 138, 83-91, doi:10.1016/0012-821X(95)00225-2.

Wilcock, W.S.D., 2004. Physical response of mid-ocean ridge hydrothermal systems to local earthquakes. Geochem. Geophys. Geosyst. 5, Q11009, doi:10.1029/2004GC000701.

\section{Figure Captions}

Figure 1. Thermal response of the Bio9 vent at East Pacific Rise 950’ N [from Sohn et al., 1998].

Figure 2. Temperature data from the three Endeavour axial valley sites. Red traces, data from thermistors located within hydrothermal fluids from vents; blue traces, data from thermistors deployed in the adjacent (non-vent) bottom water at each site. (A) Data from the bio-column thermistors at the Beach site, located in a diffuse vent within a sediment pond $200 \mathrm{~m}$ south of the MEF. The earthquake activity ( $8 \pm 15$ June 1999 ) is marked by the vertical shaded bar. Note that the temperature scale for this site is different from the other three sites shown. (B) Temperatures from the EI/MEF site, showing the slow temperature rise after the 8 June event. (C) Data from one of the Clam Bed thermistor pairs, near the High Rise vent field. (D) Temperature data from the Clam Bed site, located only a few tens of meters from those in C.

Figure 3. Cartoon of the single-pass model showing key features. For meaning of legends please see Table 1.

Figure 4. Temperature distribution for East Pacific Rise in steady state (A) for the whole system for (B) for the boundary layer $(\mathrm{C})$ near the surface.

Figure 5. Temperature distribution for Main Endeavour Field in steady state (A) for the whole system for (B) for the boundary layer (C) near the surface.

Figure 6. Temperature distribution for Main Endeavour Field in steady state (blue) and perturbed state for dike $w=1,2,10$ and $20 \mathrm{~m}$ (A) for the whole system for (B) for the boundary layer (C) near the surface. Values were plotted $\sim 25$ days after dike emplacement. 
Figure 7. Temperature at the surface (top) and mass flow rate (bottom) for Main Endeavour Field in steady state (blue) and perturbed state (other colors) for dike $w=1,2,10$ and $20 \mathrm{~m}, \sim 25$ days after diking event.

Figure 8. Temperature distribution for Main Endeavour Field in steady state (blue) and perturbed state for dike $h=250,500,750$ and $1000 \mathrm{~m}$ (A) for the whole system for (B) for the boundary layer (C) near the surface. Values were plotted $\sim 25$ days after dike emplacement.

Figure 9. Temperature at the surface (top) and mass flow rate (bottom) for Main Endeavour Field in steady state (blue) and perturbed state (other colors) for dike $h=250,500,750$ and $1000 \mathrm{~m}, \sim 25$ days after diking event.

Figure 10. Temperature distribution for EPR $9^{\circ} 50^{\prime} \mathrm{N}$ in steady state (blue) and perturbed state when $k$ in the diking zone is increased by $10 \%, 20 \%, 50 \%$ and 2 times (A) for the whole system for (B) for the boundary layer $(\mathrm{C})$ near the surface. Values were plotted $\sim 25$ days after dike emplacement.

Figure 11. Temperature at the surface (top) and mass flow rate (bottom) for EPR $9^{\circ} 50^{\prime} \mathrm{N}$ in steady state (blue) and perturbed state (other colors) when $k$ in the diking zone is increased by $10 \%, 20 \%, 50 \%$ and 2 times, $\sim 25$ days after diking event.

Figure 12. Temperature distribution for Main Endeavour Field in steady state (blue) and perturbed state when $k$ in the diking zone is increased by 10\%, 20\%, 50\% and 2 times (A) for the whole system for (B) for the boundary layer (c) near the surface. Values were plotted $\sim 25$ days after dike emplacement. Dike $w=2 \mathrm{~m}$, and $h=500 \mathrm{~m}$.

Figure 13. Temperature at the surface (top) and mass flow rate (bottom) for Main Endeavour Field in steady state (blue) and perturbed state (other colors) when $k$ in the diking zone is increased by $10 \%, 20 \%$, $50 \%$ and 2 times, $\sim 25$ days after diking event.

Figure 14. Temperature distribution for EPR $9^{\circ} 50^{\prime} \mathrm{N}$ in steady state (blue) and perturbed state for no diking scenario when $k$ in the diking zone is increased by 10\%, 20\%, 50\% and 2 times (A) for the whole system for (B) for the boundary layer (C) near the surface. Values were plotted $\sim 25$ days after the event.

Figure 15. Temperature at the surface (top) and mass flow rate (bottom) for EPR $9^{\circ} 50^{\prime} \mathrm{N}$ in steady state (blue) and perturbed state (other colors) for no diking scenario when $k$ in the diking zone is increased by $10 \%, 20 \%, 50 \%$ and 2 times, $\sim 25$ days after the event.

Figure 16. Temperature distribution for Main Endeavour Field in steady state (blue) and perturbed state for no diking scenario when $k$ in the diking zone is increased by $10 \%, 20 \%, 50 \%$ and 2 times (A) for the whole system for (B) for the boundary layer (C) near the surface. Values were plotted $\sim 25$ days after the event.

Figure 17. Temperature at the surface (top) and mass flow rate (bottom) for Main Endeavour Field in steady state (blue) and perturbed state (other colors) for no diking scenario when $k$ in the diking zone is increased by $10 \%, 20 \%, 50 \%$ and 2 times, $\sim 25$ days after the event. 
Fig. 1

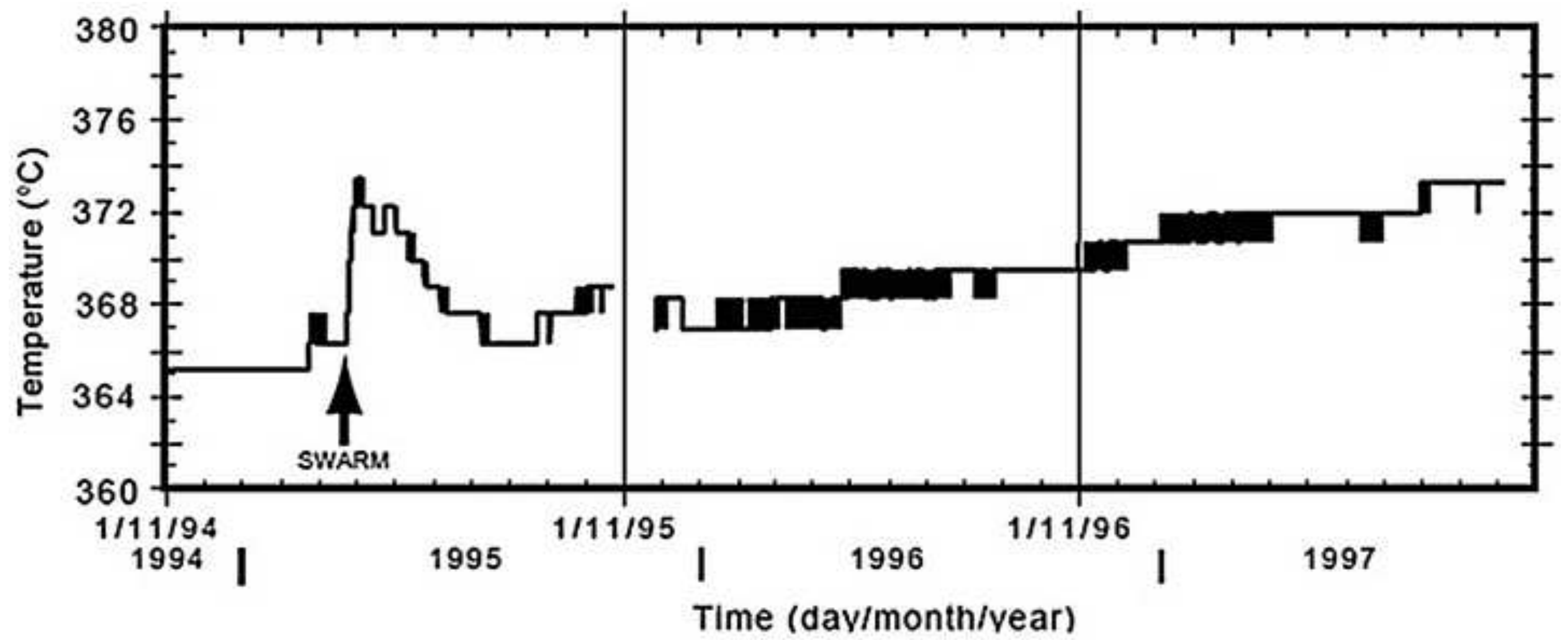




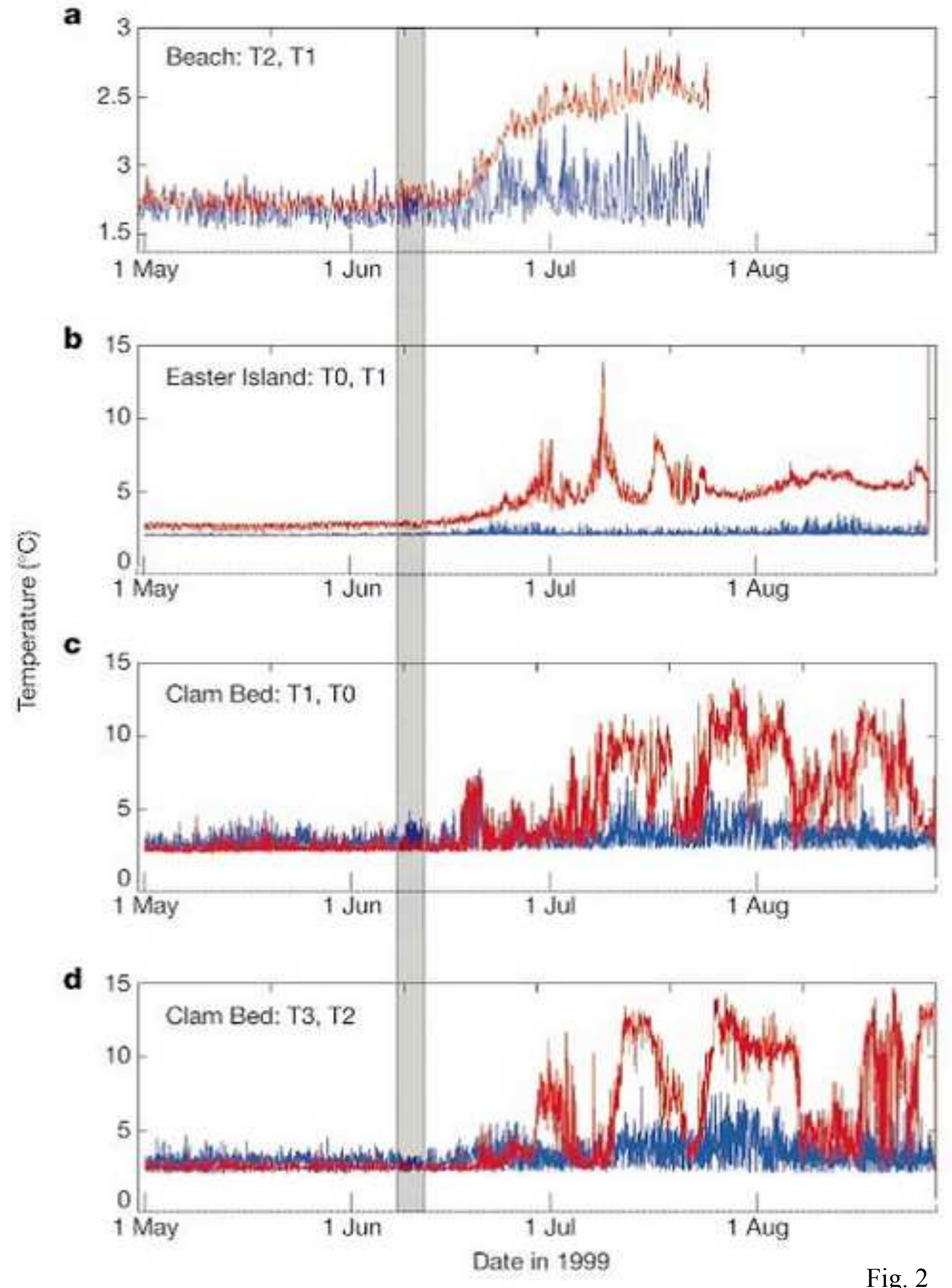




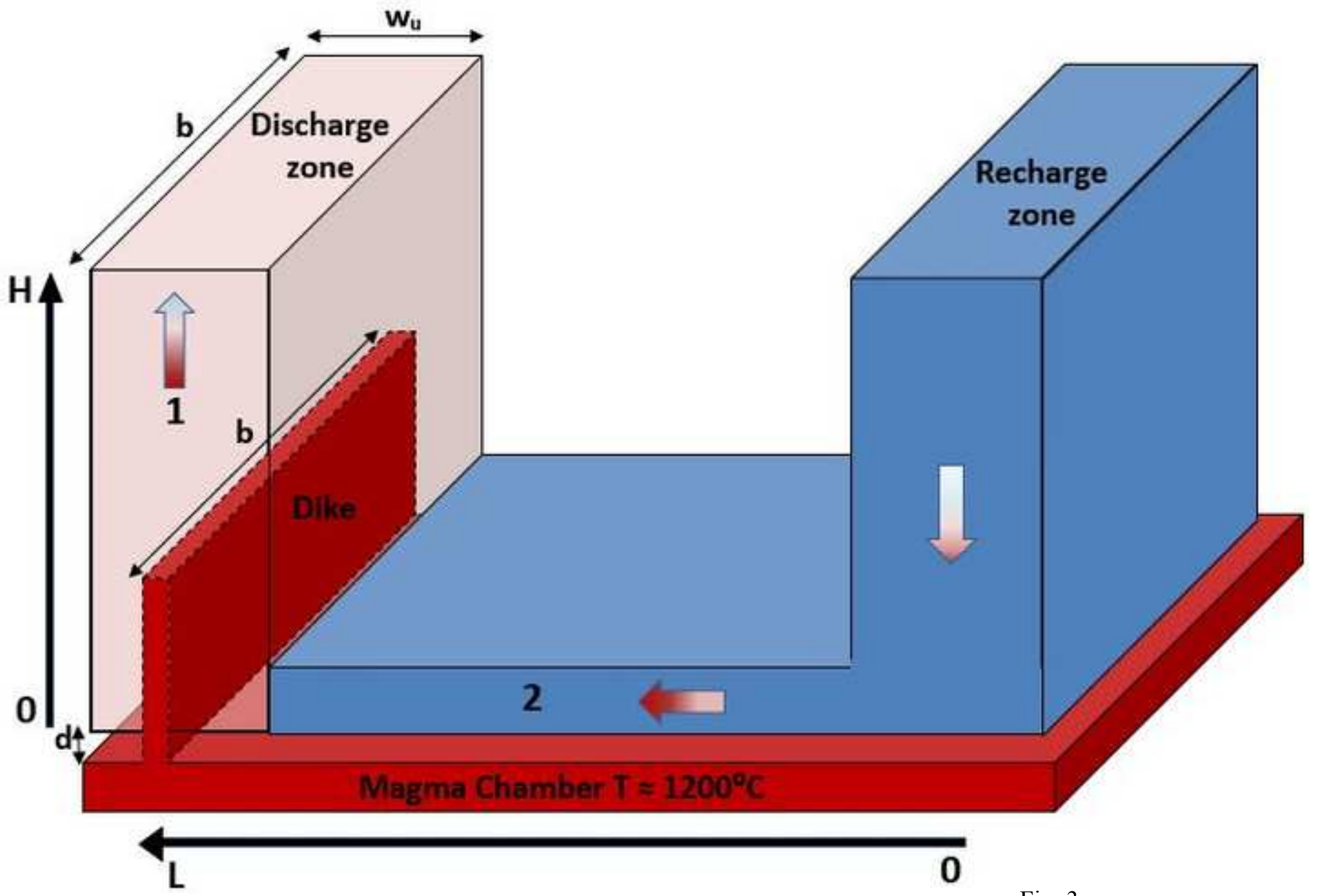

Fig. 3 
a.Temperature in the flow path

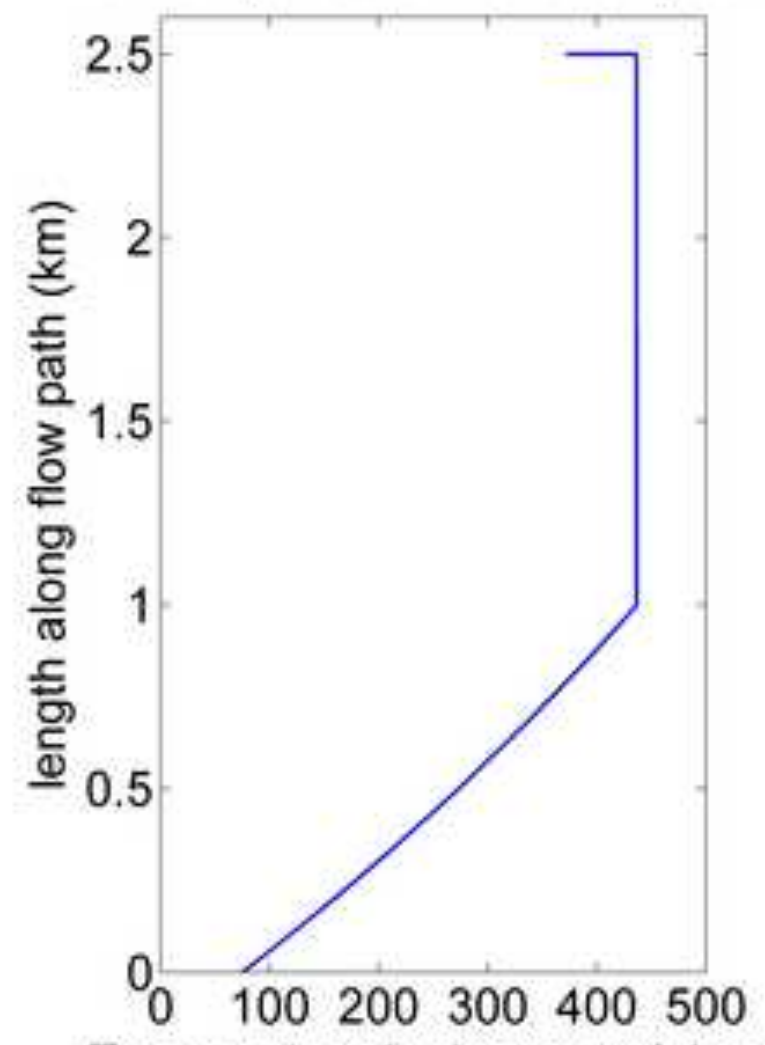

Temperature in degree celsisus b. Temperature in the boundary layer

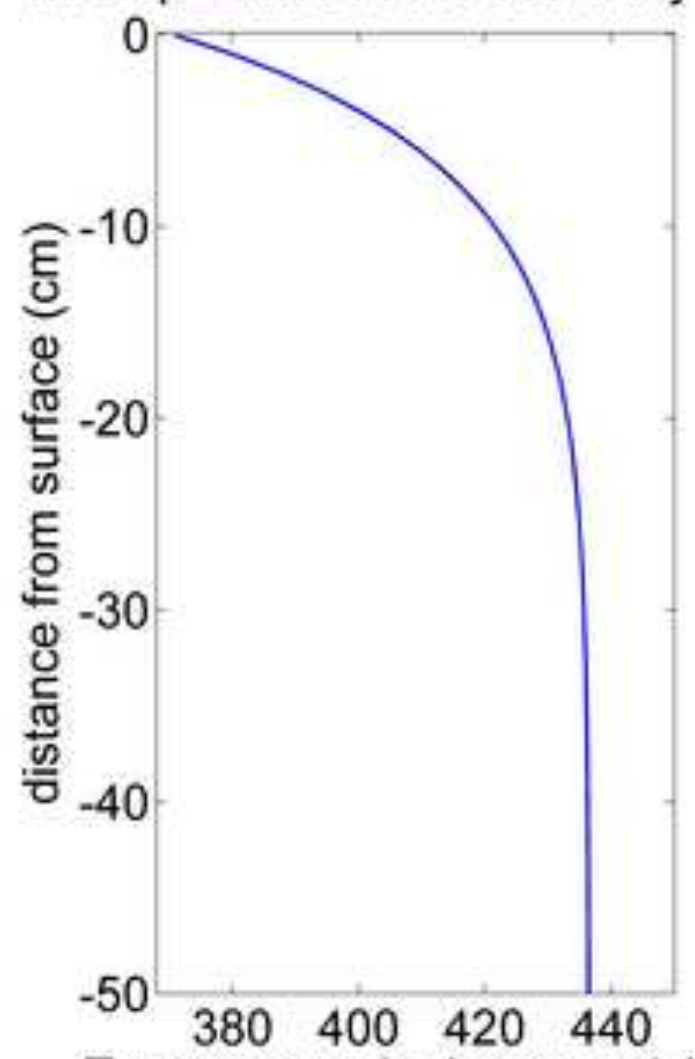

Temperature in degree celsius
c.Temperature near the surface

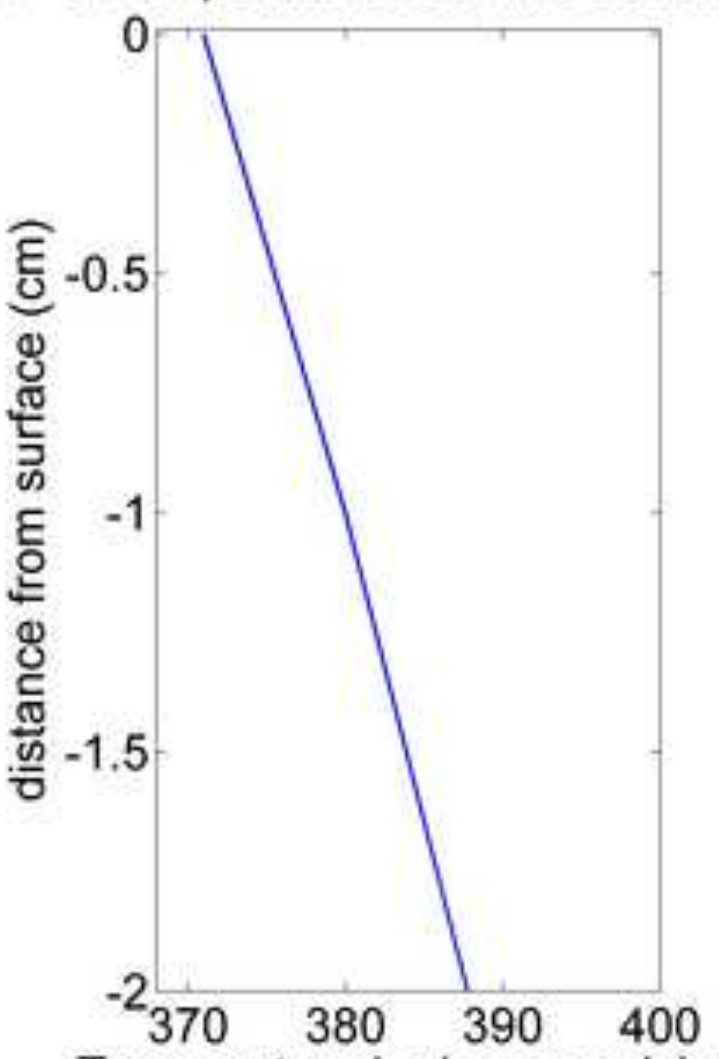

Temperature in degree celsius

Fig. 4 
a.Temperature in the flow path

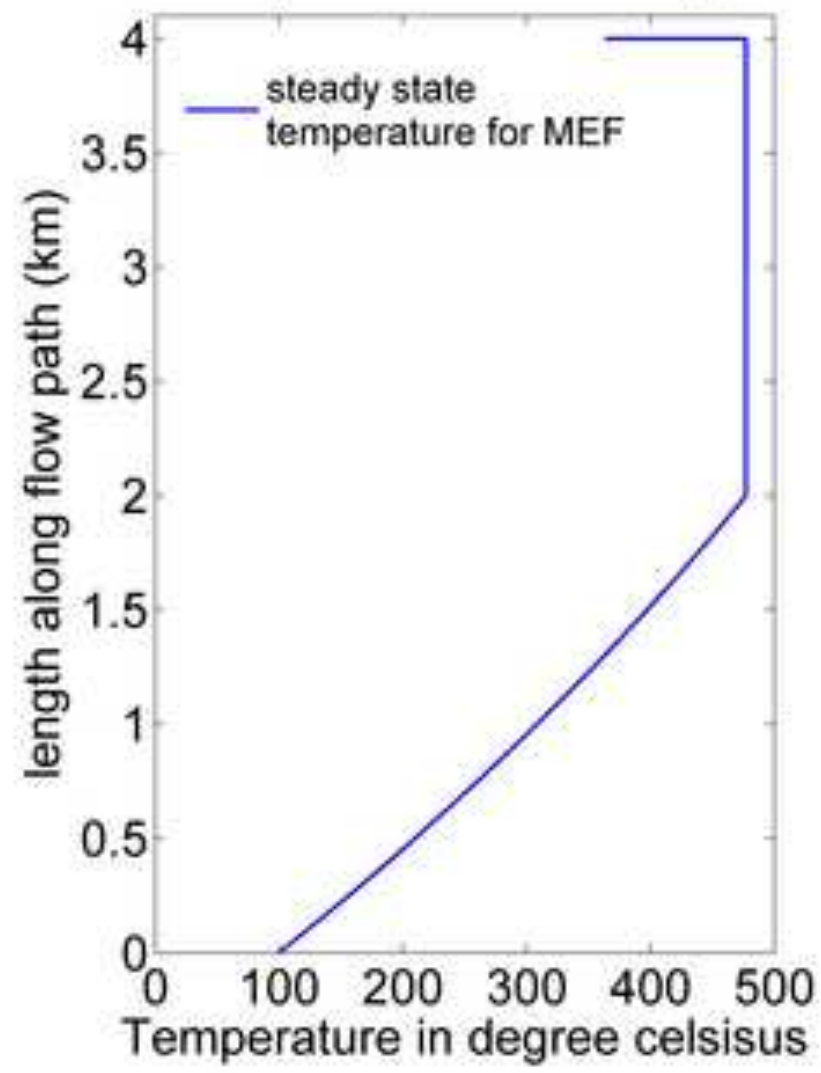

b. Temperature in the boundary layer

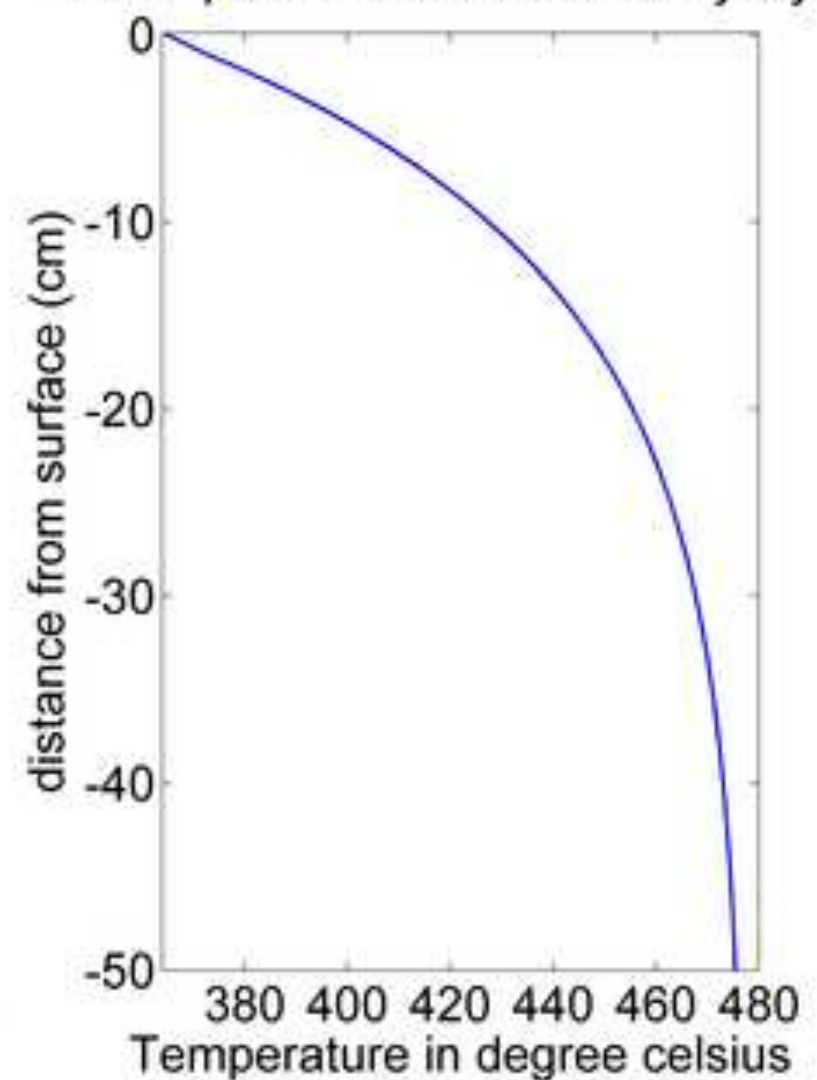

c.Temperature near the surface

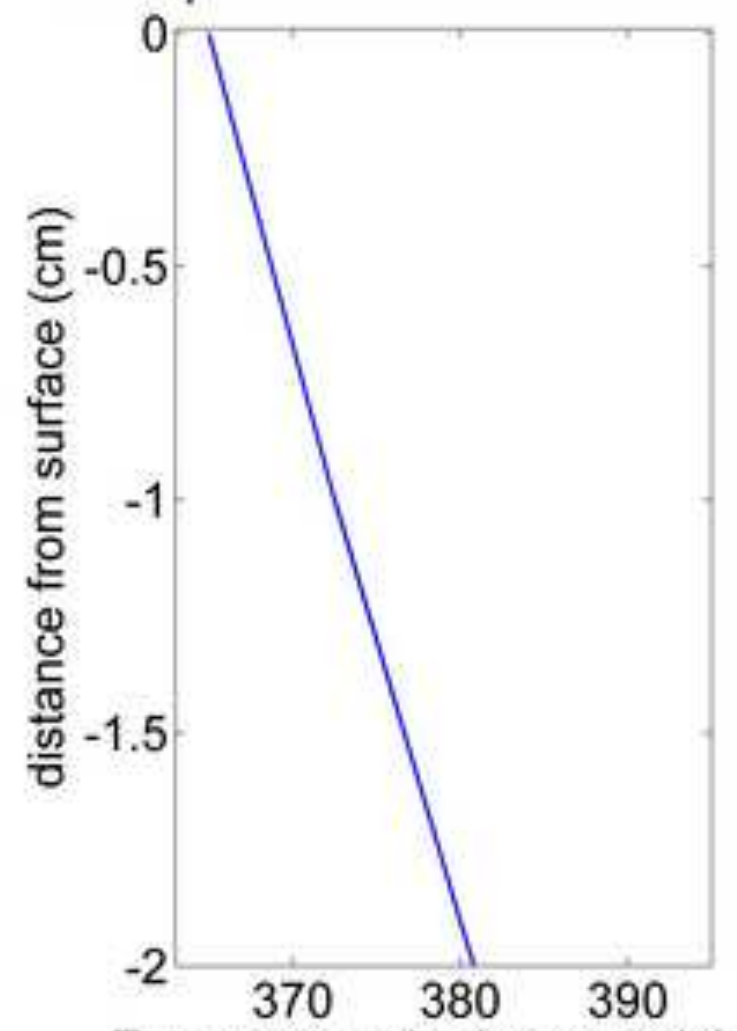

Temperature in degree celsius

Fig. 5 


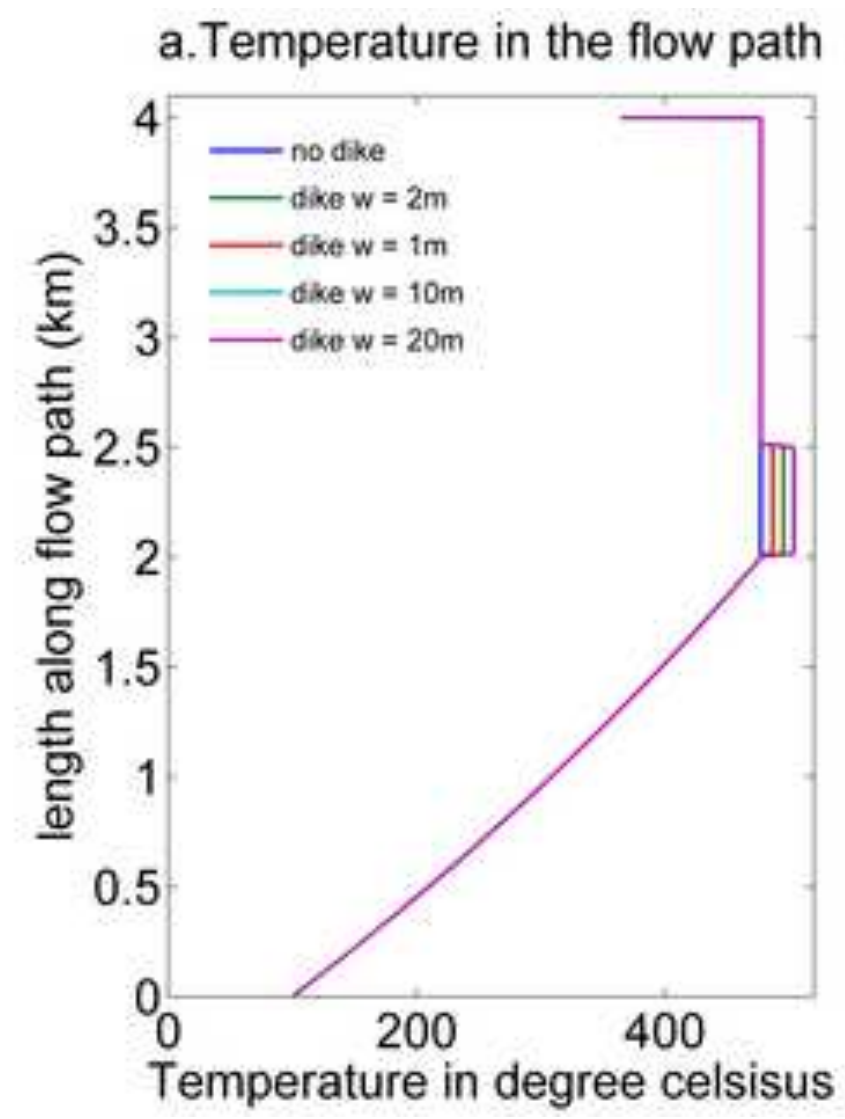

b. Temperature in the boundary layer
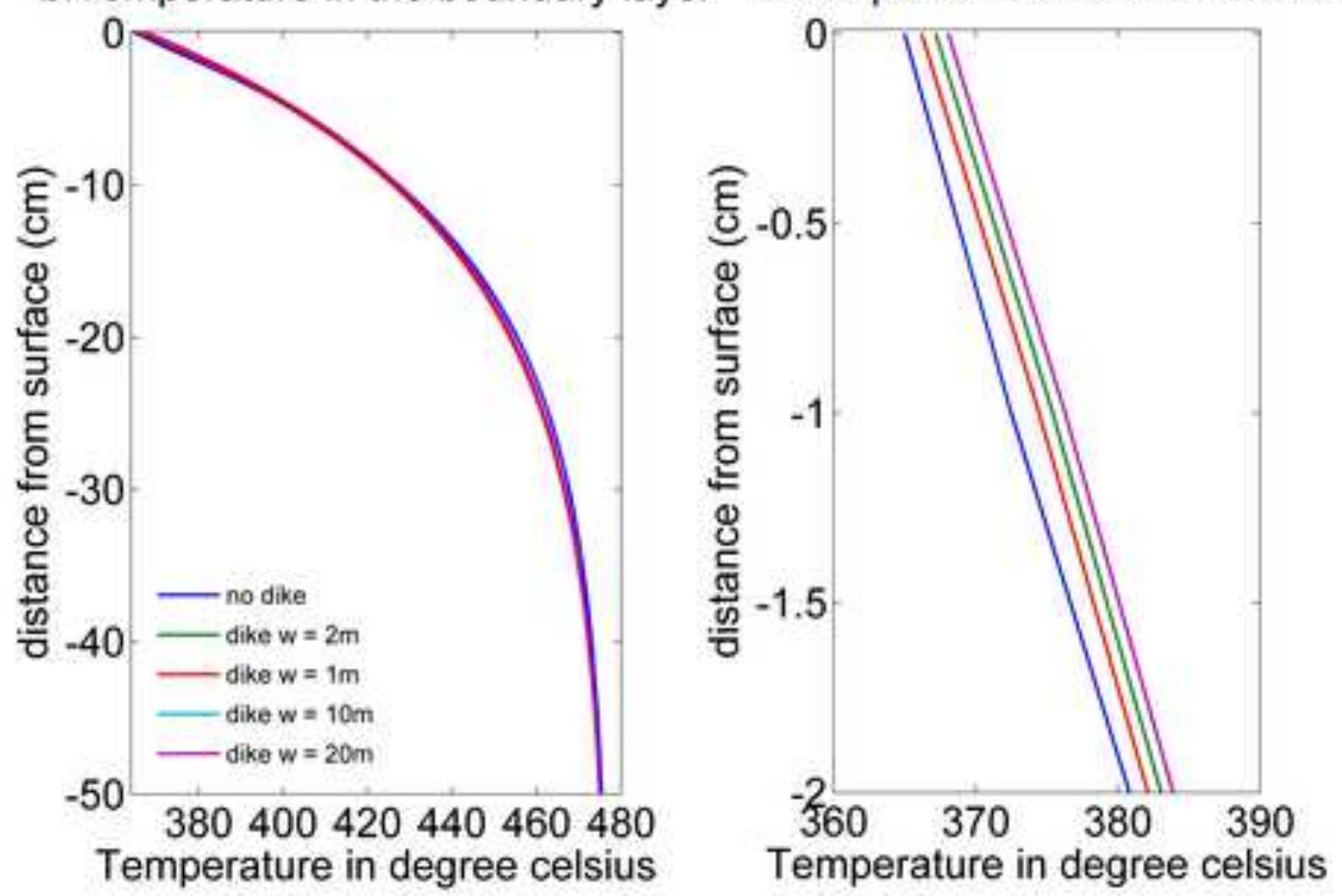

Fig. 6 


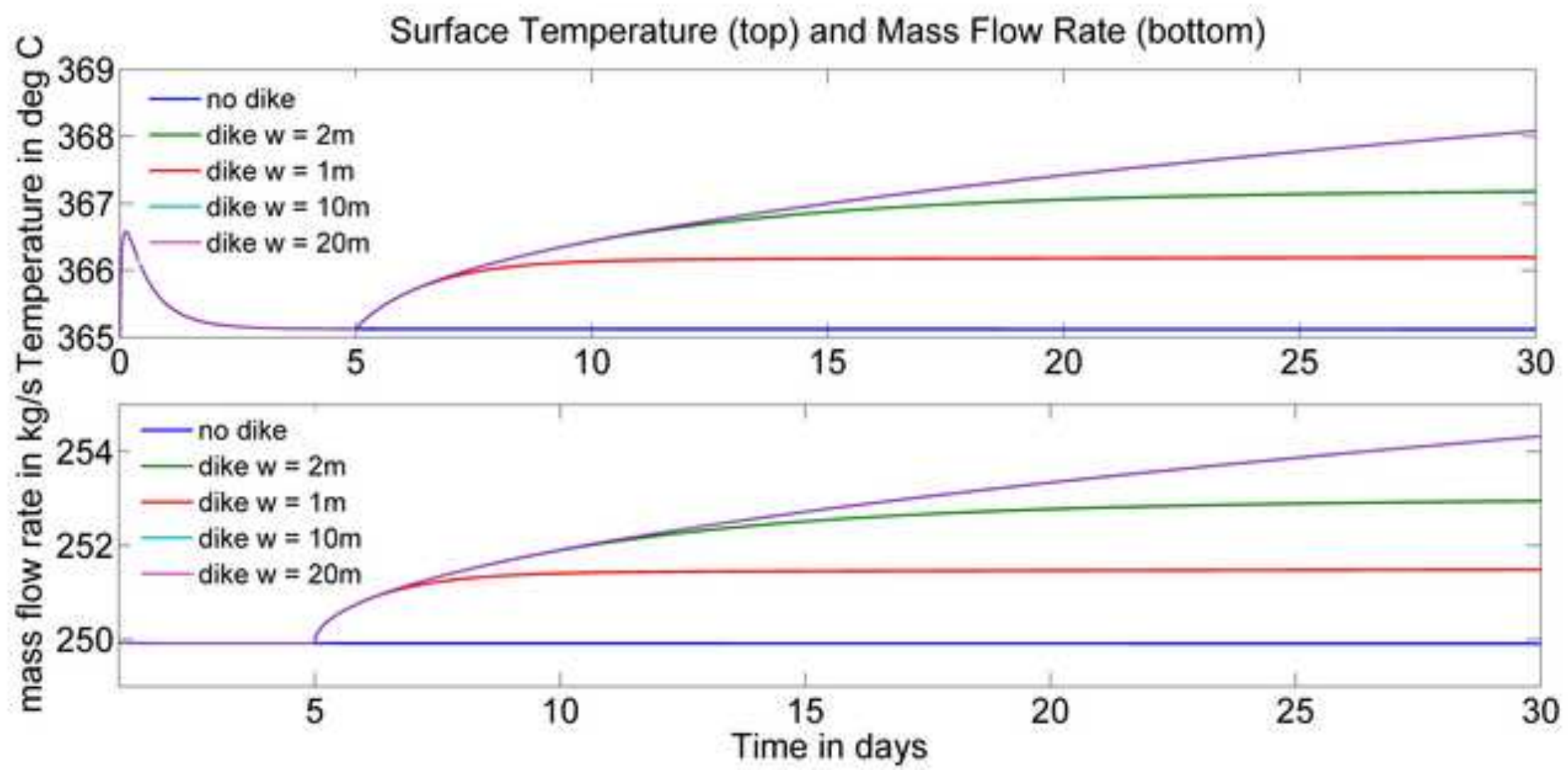

Fig. 7 

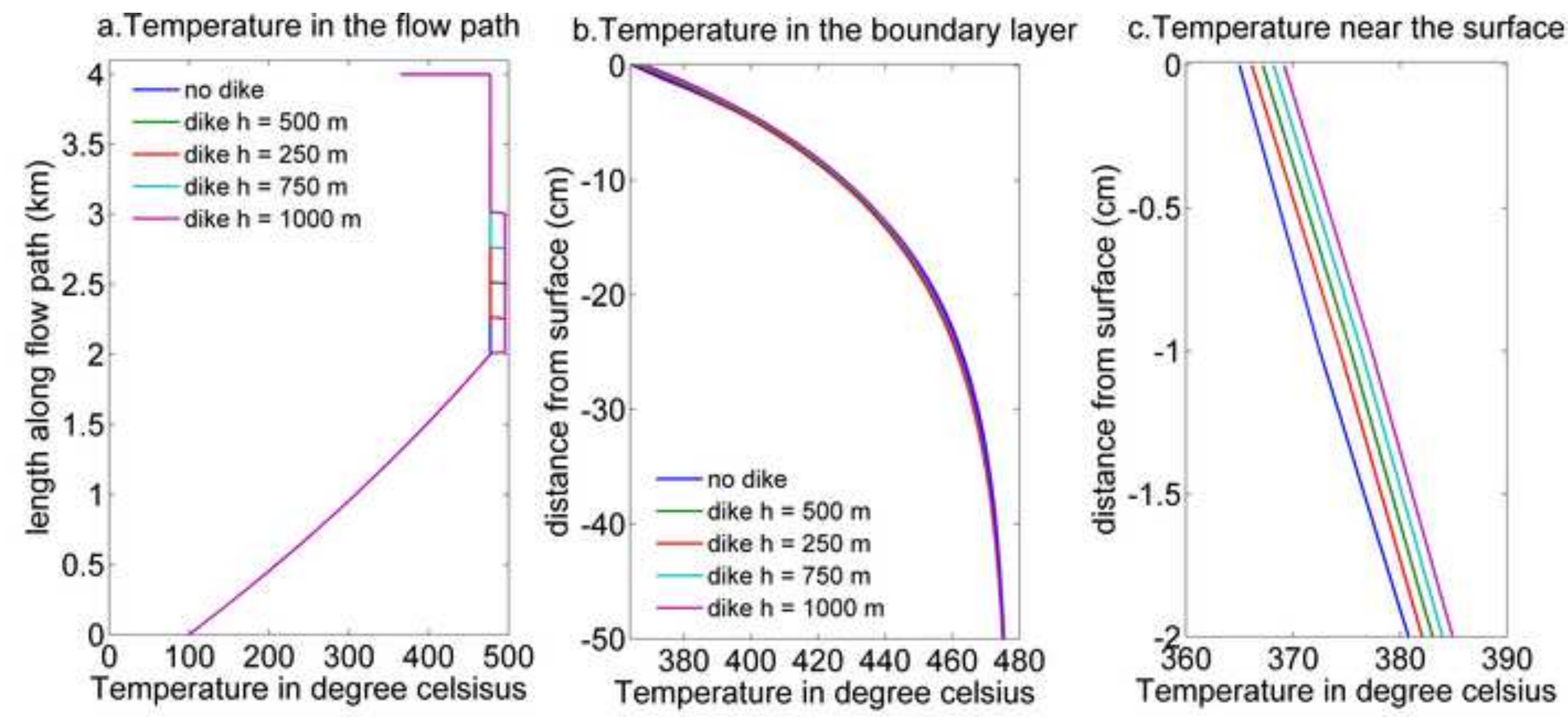

Fig. 8 


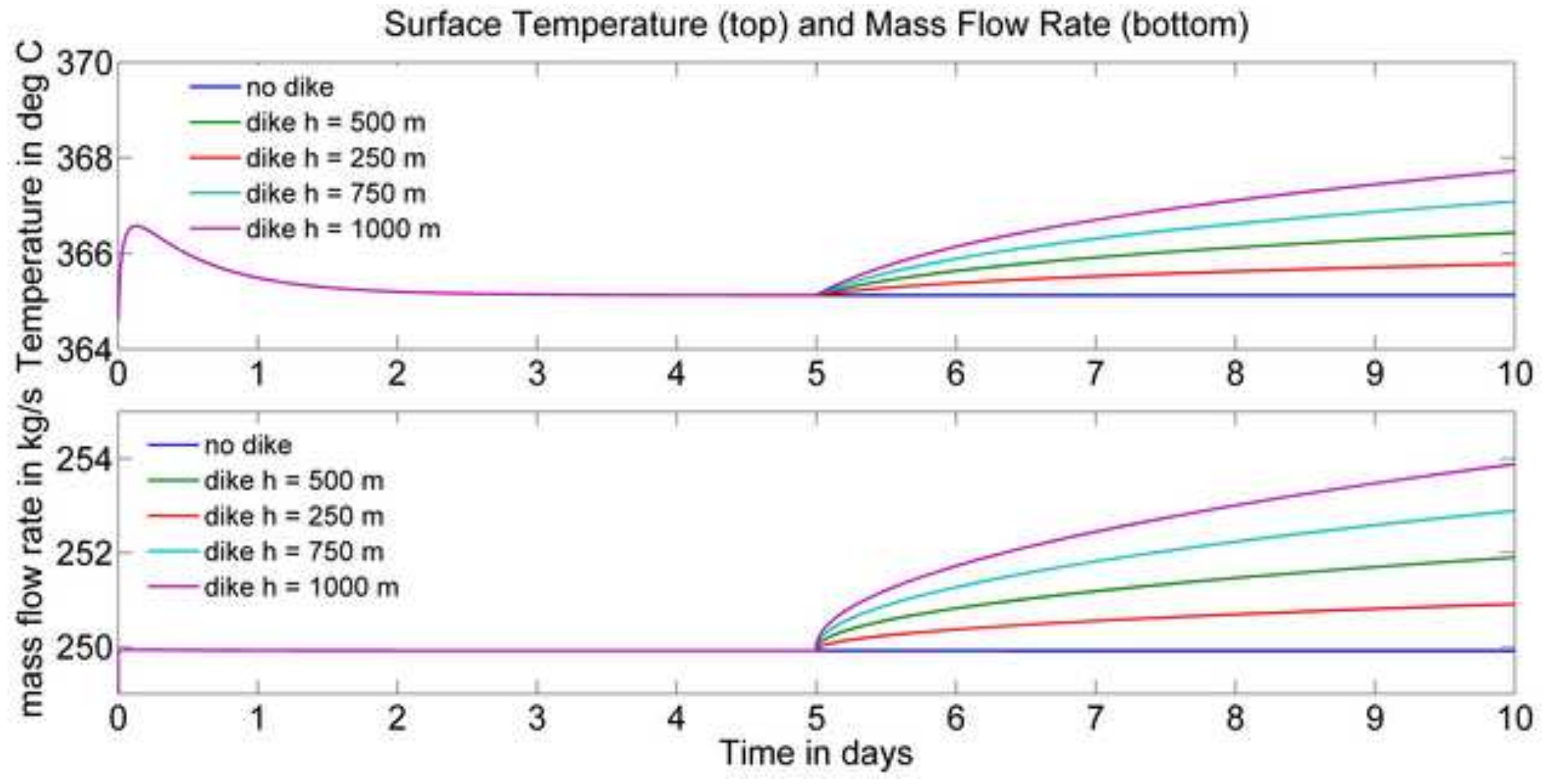

Fig. 9 
a.Temperature in the flow path

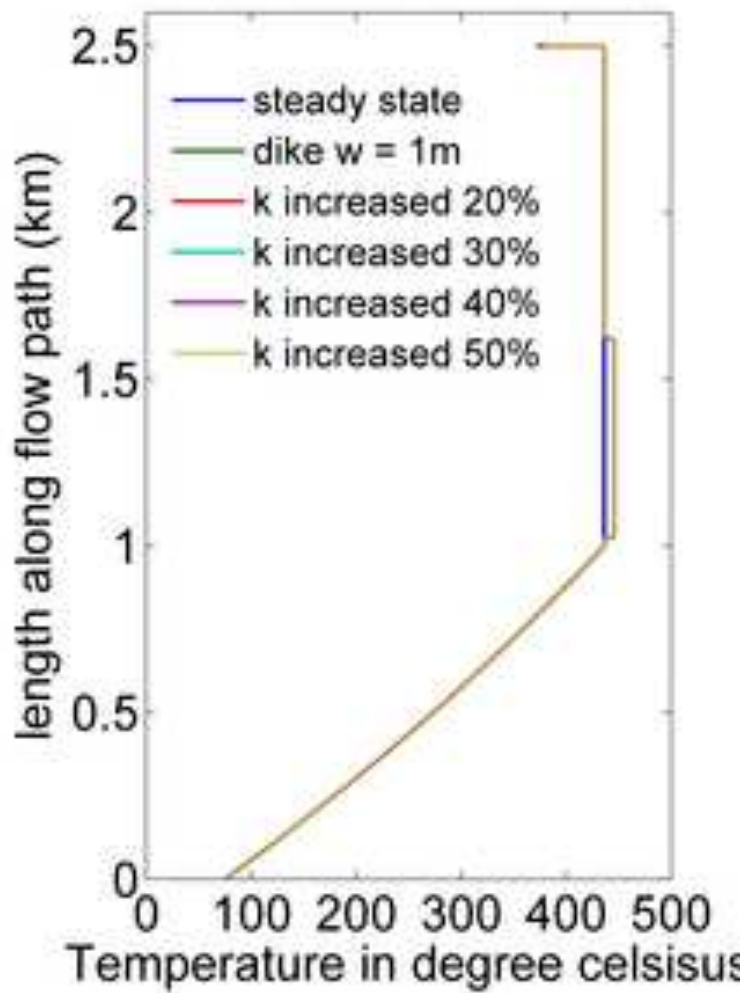

b. Temperature in the boundary layer

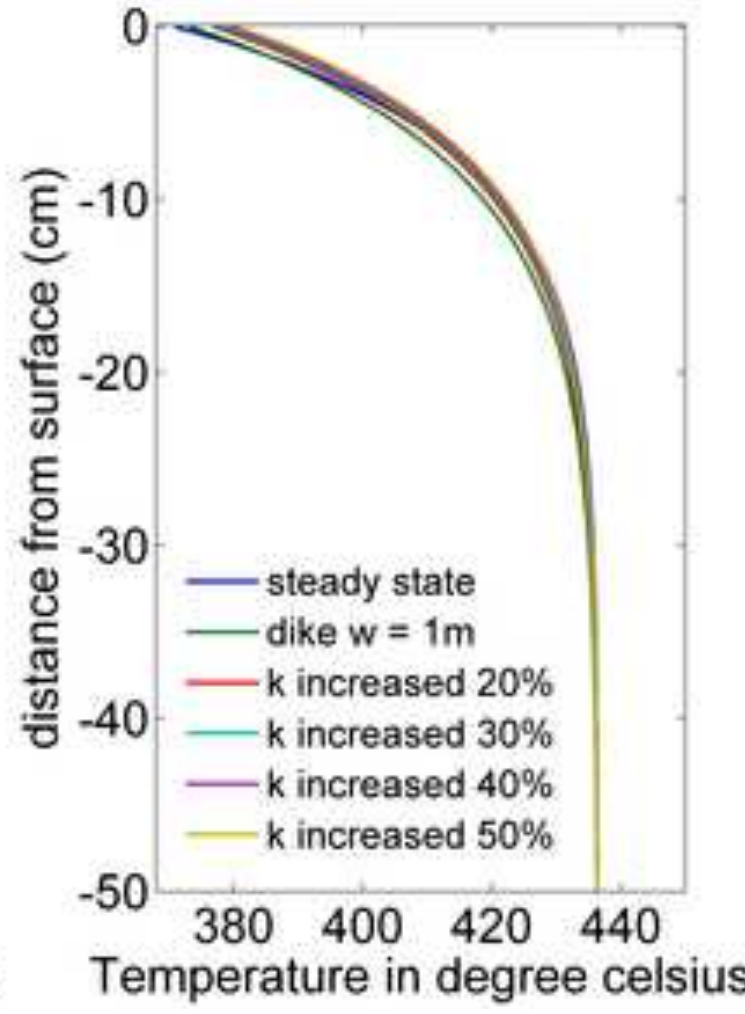

c. Temperature near the surface

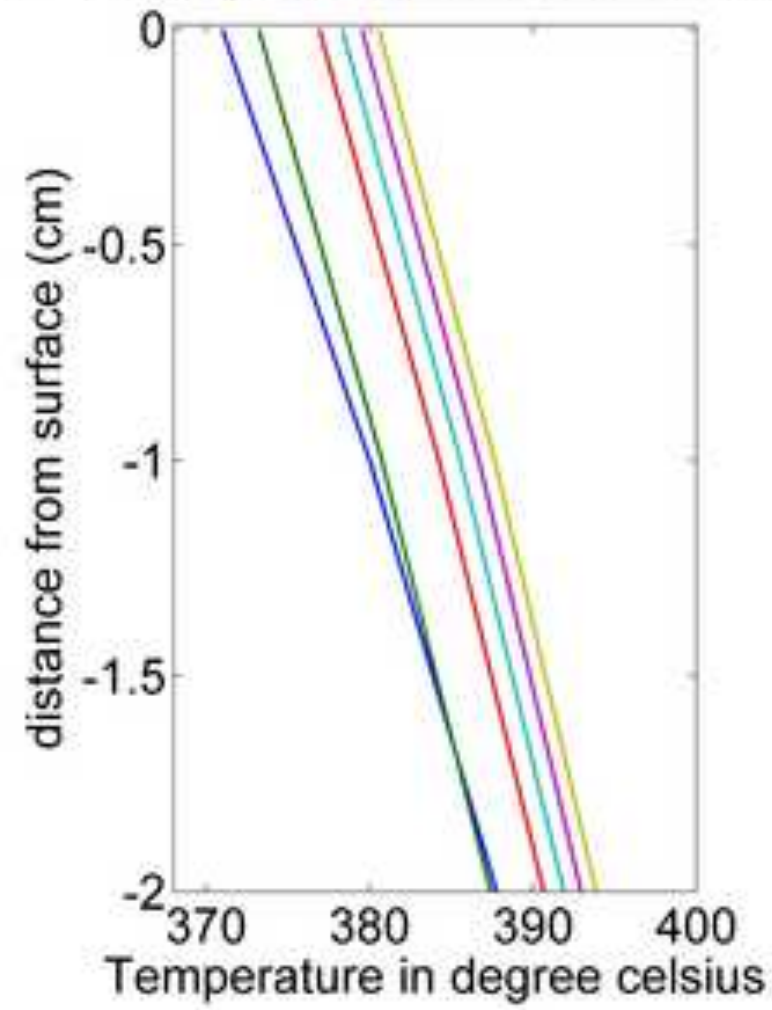

Fig. 10 


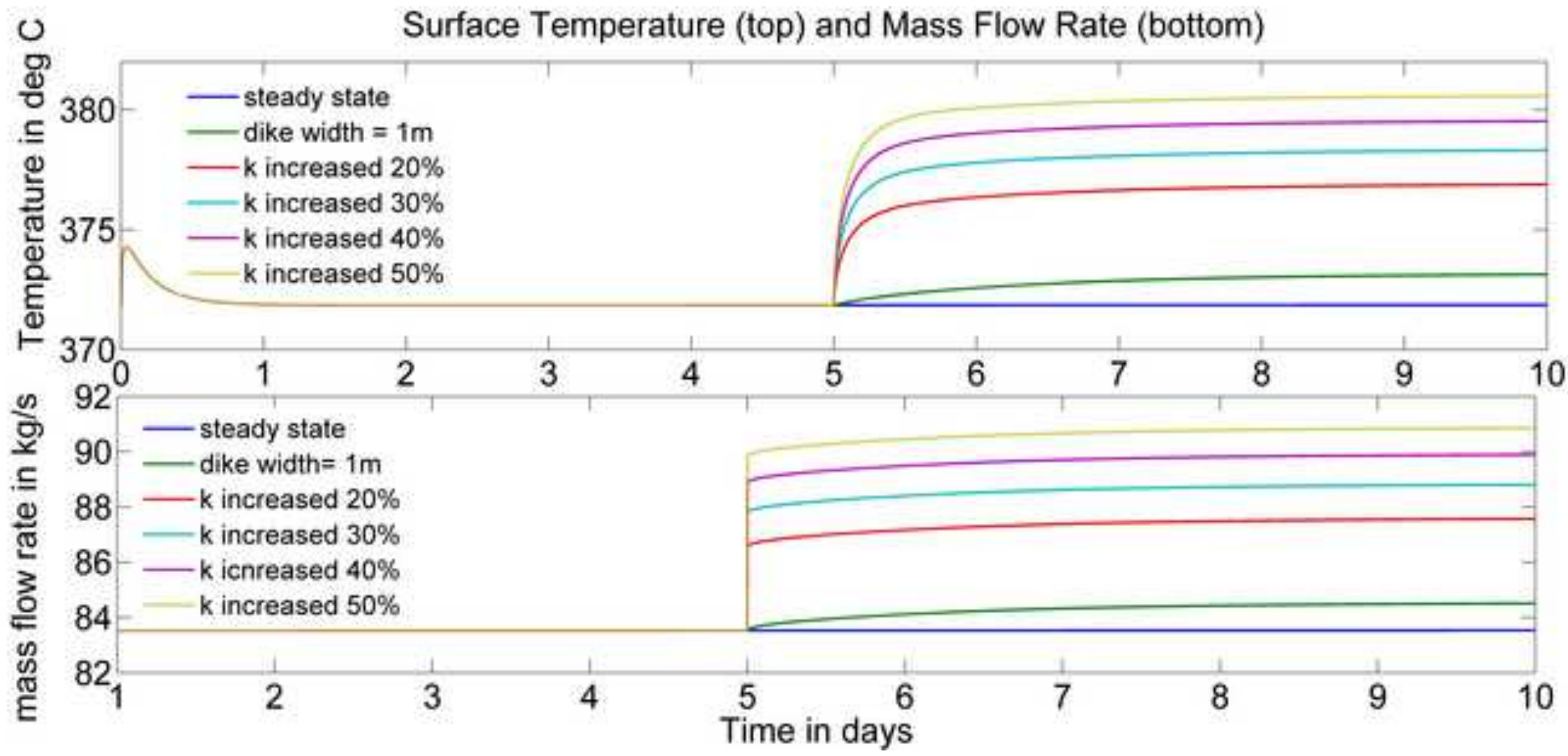

Fig. 11 
a.Temperature in the flow path

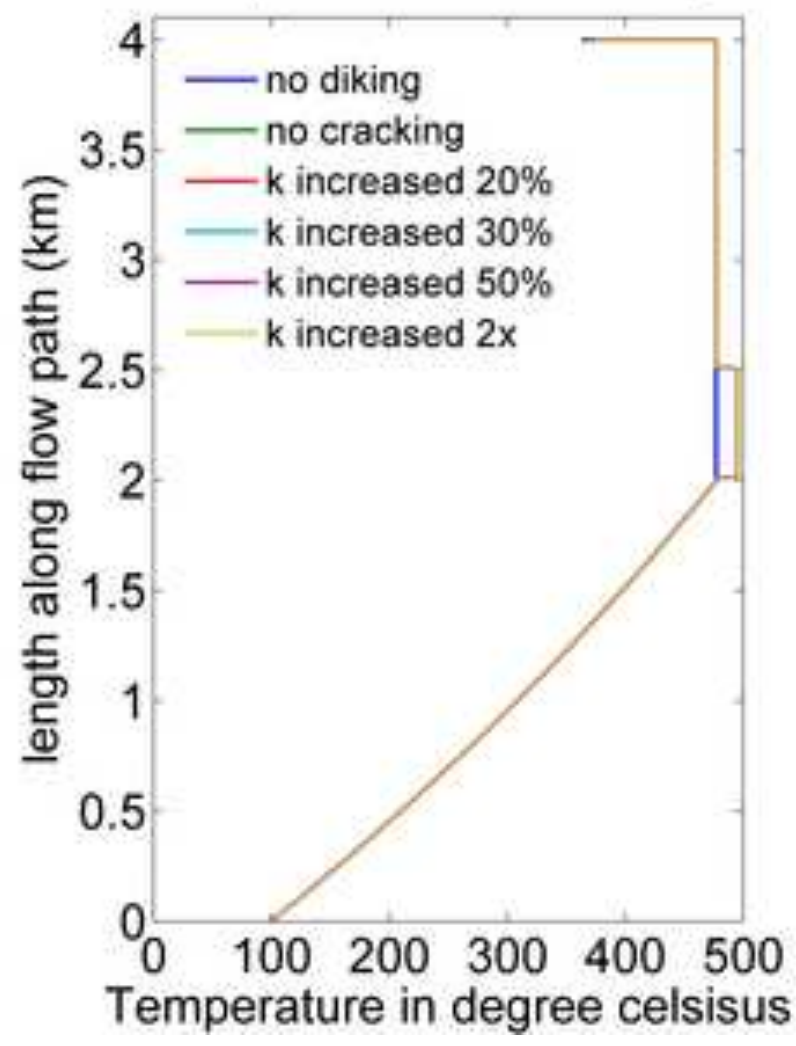

b. Temperature in the boundary layer

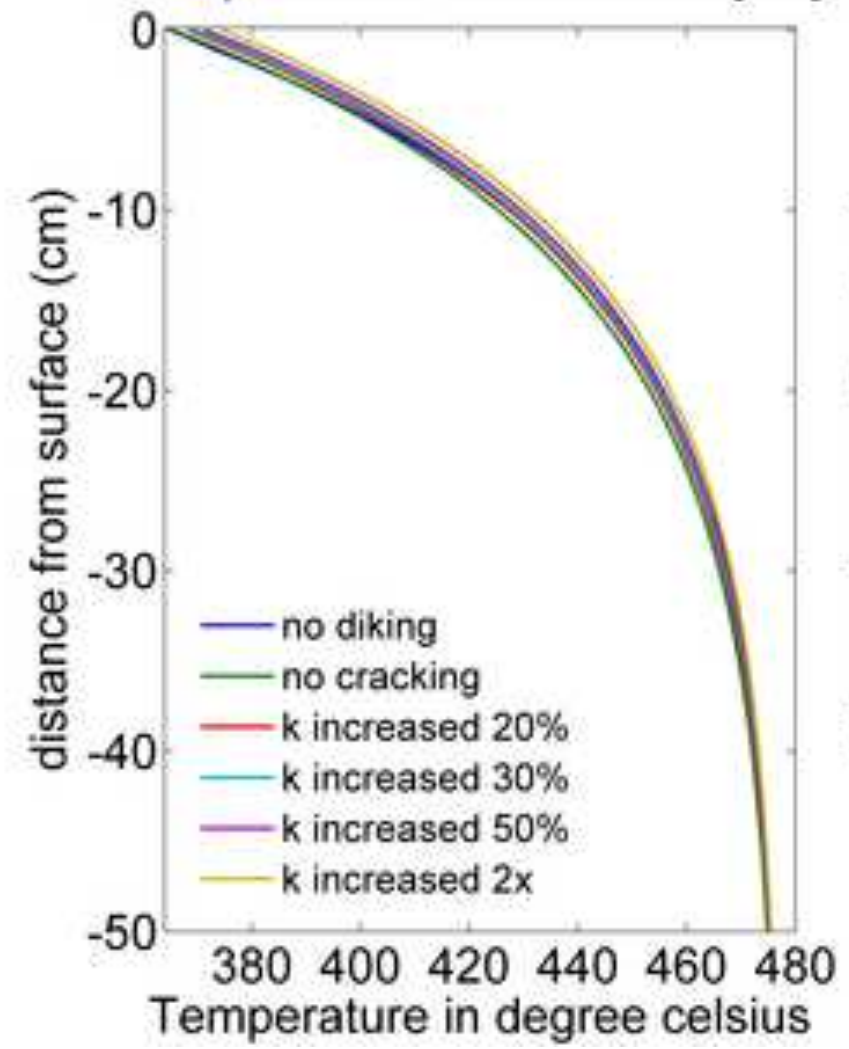

c. Temperature near the surface

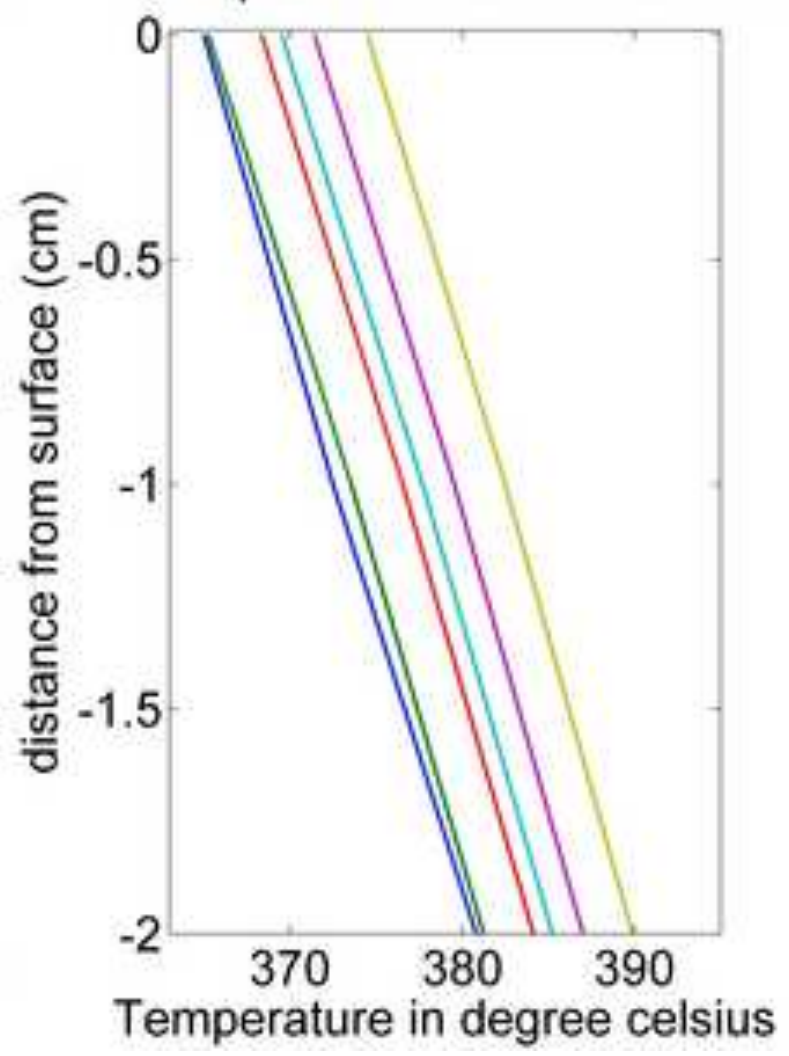

Fig. 12 
Surface Temperature (top) and Mass Flow Rate (bottom)
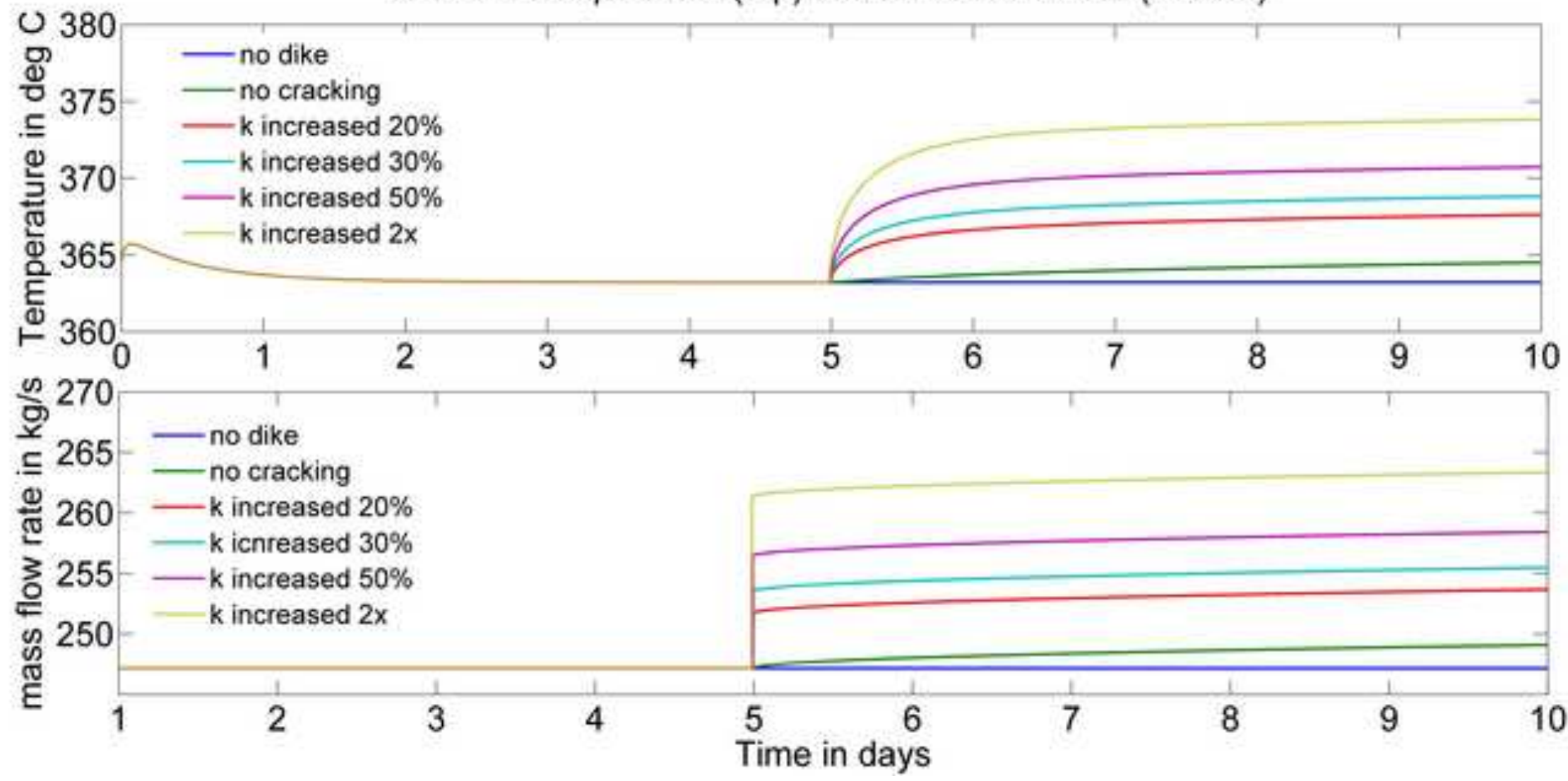

Fig. 13 
a.Temperature in the flow path

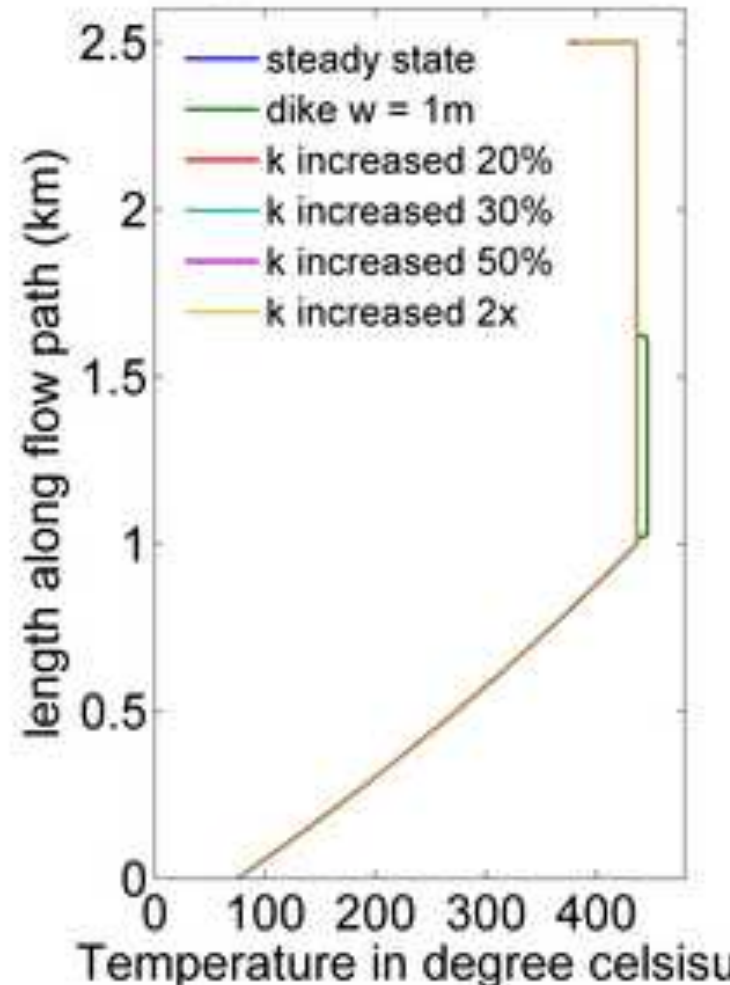

b.Temperature in the boundary layer

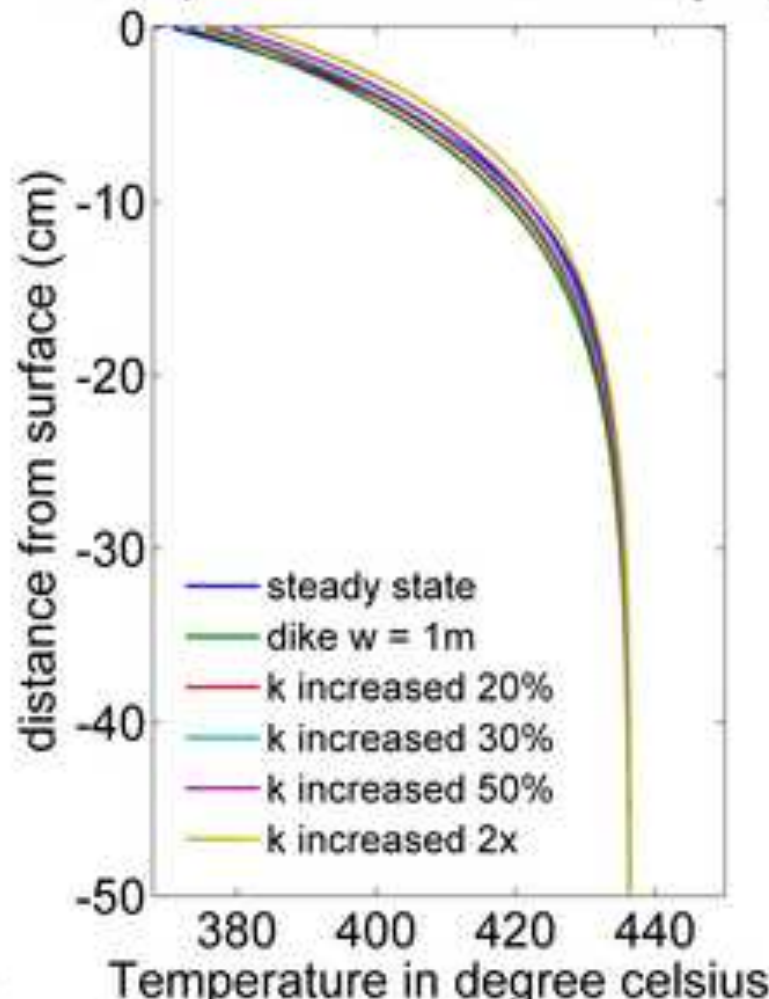

c. Temperature near the surface

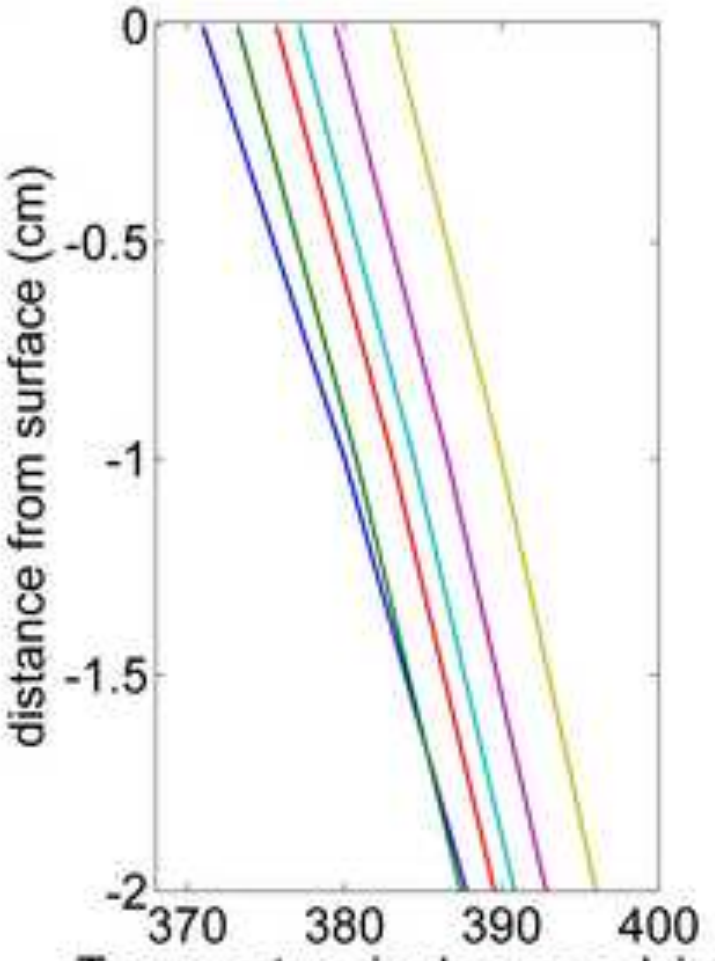

Temperature in degree celsius

Fig. 14 


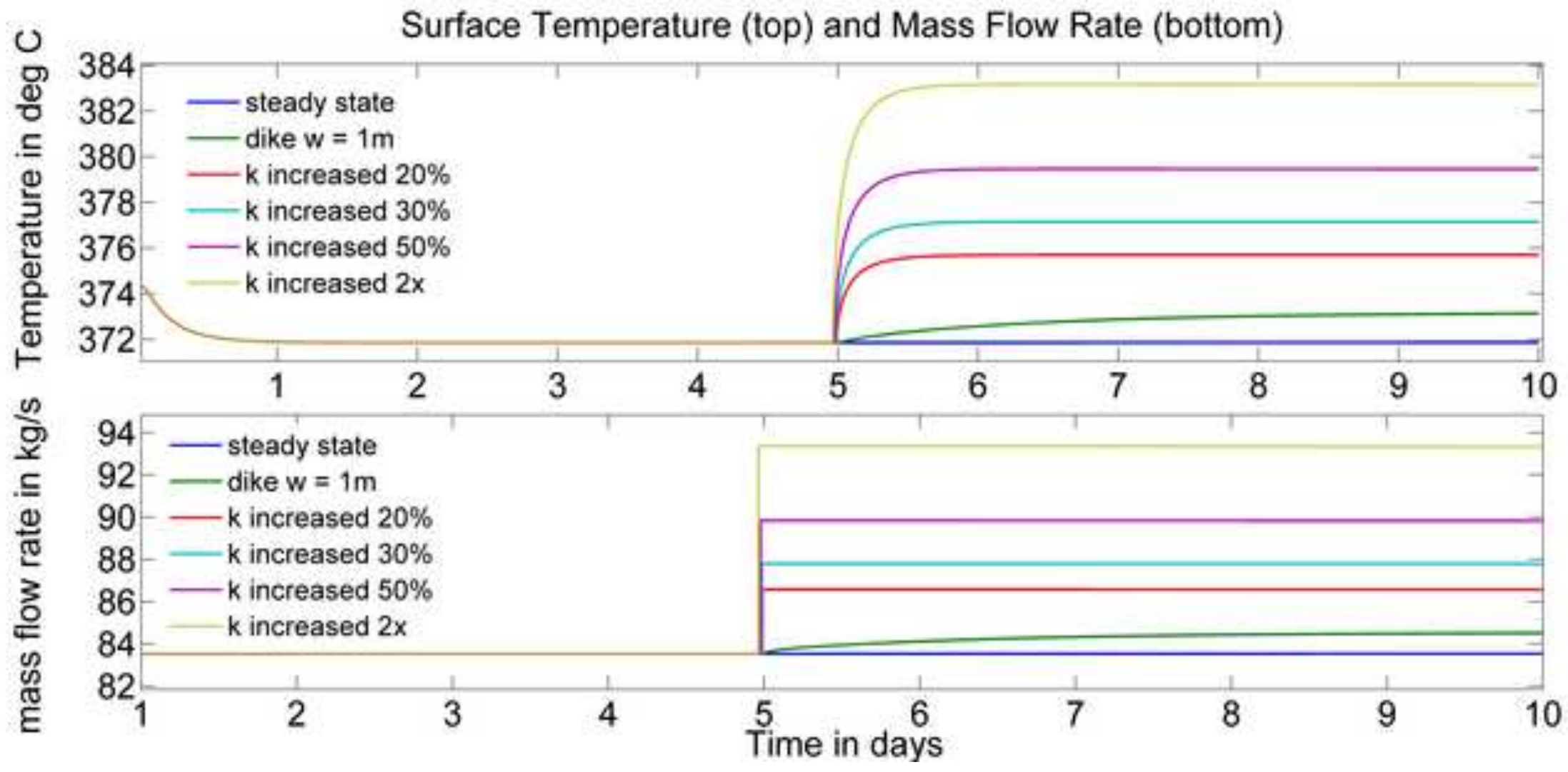

Fig. 15 
a.Temperature in the flow path

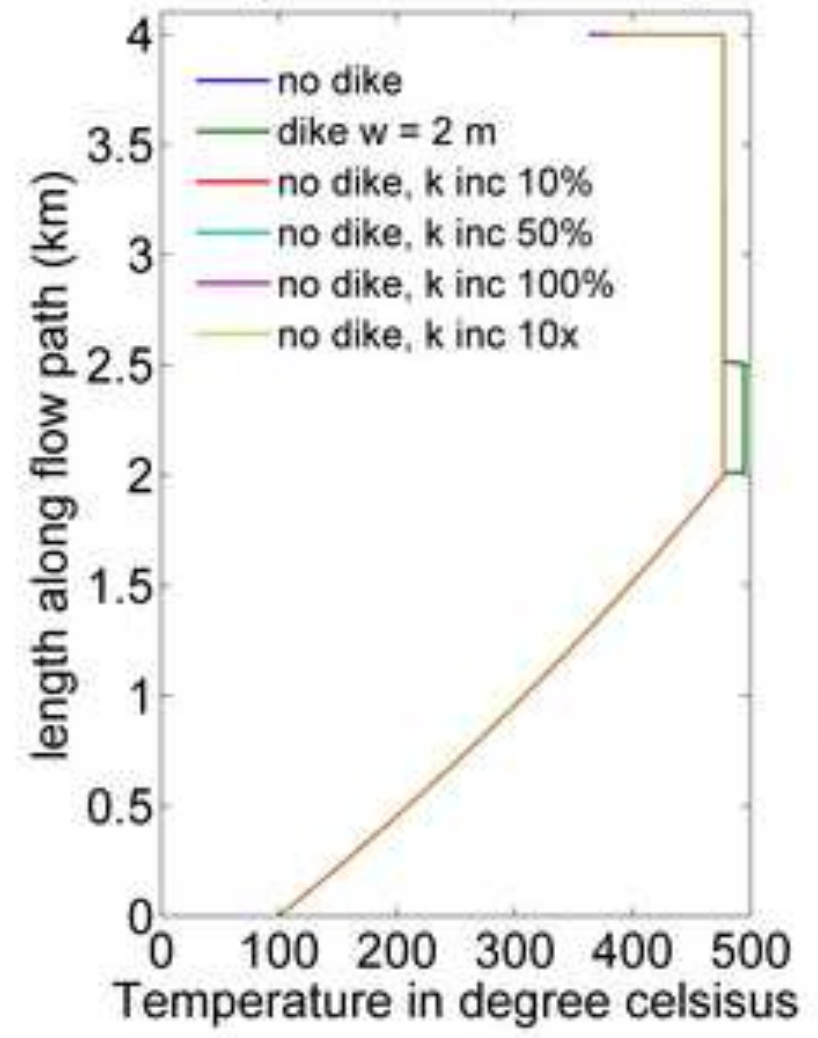

b.Temperature in the boundary layer

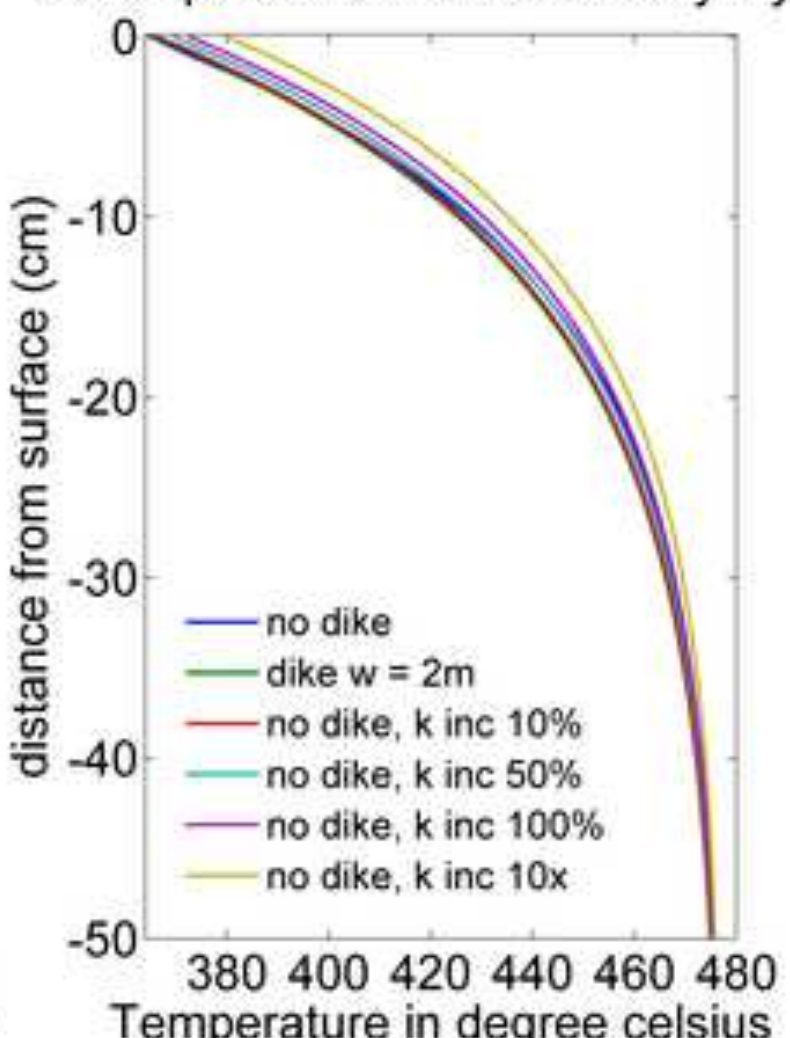

c. Temperature near the surface

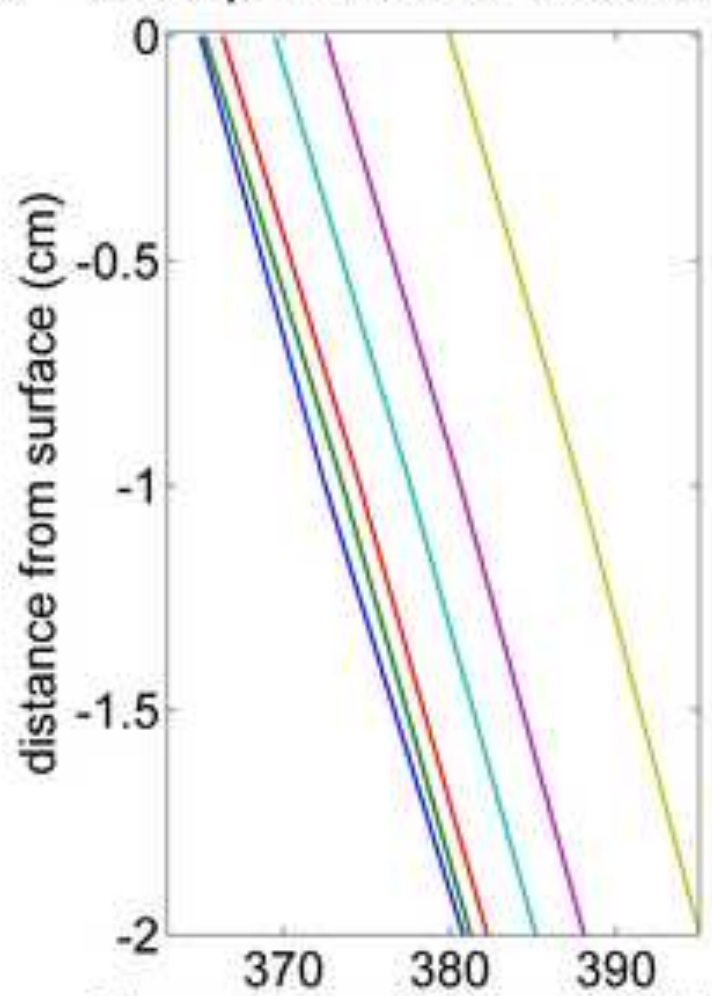

Temperature in degree celsius

Fig. 16 
Surface Temperature (top) and Mass Flow Rate (bottom)

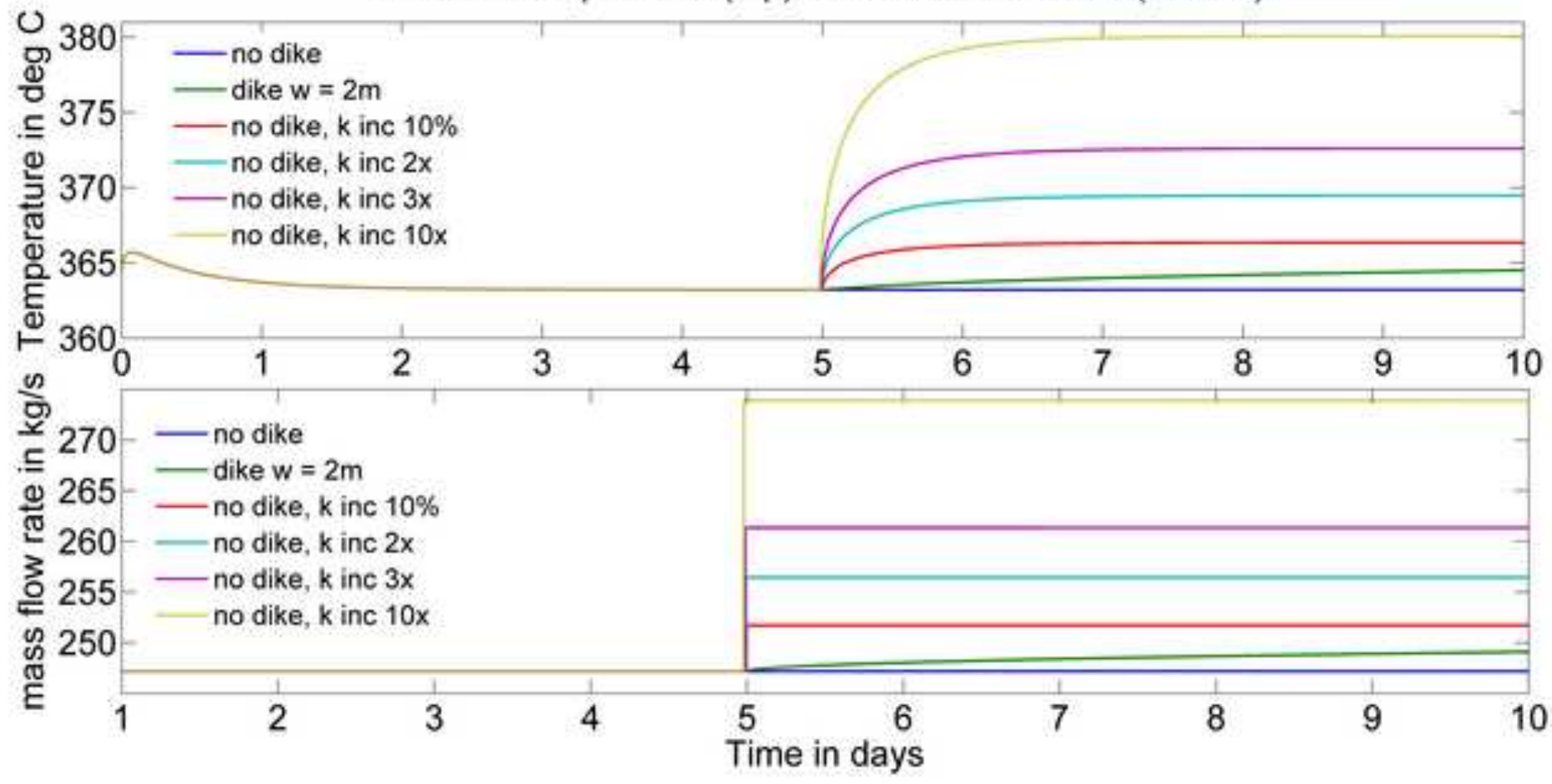

Fig. 17 